\title{
Crowdsourcing and open innovation: a systematic literature review, an integrated framework and a research agenda
}

\author{
Livio Cricelli ${ }^{1}\left({ }^{\circ} \cdot\right.$ Michele Grimaldi $^{2}\left([) \cdot\right.$ Silvia Vermicelli $^{3}[$
}

Received: 15 November 2020 / Accepted: 5 July 2021 / Published online: 22 July 2021

(c) The Author(s) 2021

\begin{abstract}
In recent years, Open Innovation (OI) and crowdsourcing have been very popular topics in the innovation management literature, attracting significant interest and attention, and inspiring a rich production of publications. Although these two topics share common themes and address similar managerial challenges, to the best of our knowledge, there is no systematic literature review that digs deep into the intersection of both fields. To fill in this gap a joint review of crowdsourcing and OI topics is both timely and of interest. Therefore, the main objective of this study is to carry out a comprehensive, systematic, and objective review of academic research to help shed light on the relationship between OI and crowdsourcing. For this purpose, we reviewed the literature published on these two topics between 2008 and 2019, applying two bibliometric techniques, co-citation and co-word analysis. We obtained the following results: (i) we provide a qualitative analysis of the emerging and trending themes, (ii) we discuss a characterization of the intersection between OI and crowdsourcing, identifying four dimensions (strategic, managerial, behavioral, and technological), (iii) we present a schematic reconceptualization of the thematic clusters, proposing an integrated view. We conclude by suggesting promising opportunities for future research.
\end{abstract}

Keywords Crowdsourcing · Open innovation · Systematic literature review · Co-word analysis

Mathematics Subject Classification 90-02

Silvia Vermicelli

silvia.vermicelli@uniroma2.it

Extended author information available on the last page of the article 


\section{Introduction}

Open Innovation (hereinafter referred to as "OI") and crowdsourcing have been and still are hot issues in the innovation management literature. OI has attracted significant interest, stimulating the publication of hundreds of articles over the course of the last decade (Dahlander and Gann 2010; Huizingh 2011; Bogers and West 2012; Remneland Wikhamn and Wikhamn 2013; Lopez-Vega et al. 2016; Randhawa et al. 2016; Moellers et al. 2018; Nylund et al. 2020) similarly, according to Liang and He (2017), crowdsourcing has gained increasing attention from scholars in a broad range of fields such as computer science, engineering, information system, business, and economics (Vuković 2009; Whitla 2009; Saxton et al. 2013; Geiger and Schader 2014; Zhao and Zhu 2014; Ghezzi et al. 2018; Devece et al. 2019). OI, a new paradigm introduced by Chesbrough in 2003, assumes that an organization can enhance its innovative capabilities through its interactions with other organizations (Chesbrough 2003a, b). OI is about the innovation capability deriving from the external interactions among organizations, which may follow two distinct directions: inbound OI and outbound OI (Gassmann et al. 2010; Huizingh 2011). Inbound OI (outside-in process) refers to the internal use of external knowledge, from partners, customers, universities, research organizations. Outbound OI (inside-out process) refers to external exploitation of internal knowledge, through selling patents, direct licensing, or by other means. Crowdsourcing is a complex phenomenon, and this aspect has emerged since its origins. Howe coined the term "crowdsourcing" in Wired Magazine in 2006, as a compound word of crowd and outsourcing to indicate the practice of turning to a body of people (the crowd) to obtain needed knowledge, carry out specific tasks, involve online communities in solving problems. In 2008, Howe proposed four types of crowdsourcing that focus on the ways that various applications function: crowd wisdom or collective intelligence, crowd creation or user-generated content, crowdvoting, crowdfunding (Brabham 2013). Given its multidisciplinary nature, it is difficult to define it: in the expert literature, we can find a variety of definitions, which look at crowdsourcing from different points of view (Estellés-Arolas and González-Ladrón-de-Guevara 2012; Saxton et al. 2013; Geiger and Schader 2014; Zhao and Zhu 2014). Recently, Ghezzi et al. (2018) in their review affirmed that "research into crowdsourcing originated from - and, in turn, feeds into - the streams of OI and co-creation". There is, however, a growing stream of research that considers crowdsourcing applied for OI (Merz 2018). Thanks to its adaptability, crowdsourcing could be an effective and powerful practice, and it could have great potential in operationalizing OI strategies. According to Albors et al. (2008), OI and crowdsourcing are samples of the same learning paradigm, as knowledge is distributed and the opening of a firm's R\&D processes can be a source of competitive advantage (Palacios et al. 2016). Moreover, as Bogers and West (2012) emphasized, crowdsourcing is consistent with the OI paradigm. Thus-from a strategic point of view-it must be clear that the "crowd is being asked to share its knowledge as users to improve its own experience" (Buettner 2015). Silva and Ramos (2011) emphasize that crowdsourcing innovation stems from the new paradigm of OI, based on the premise of opening up the innovation process benefiting 
from existing knowledge and ideas beyond the borders of the company, using the principle of opening the innovating process to a crowd. In a similar vein, Stanko et al. (2017) include crowdsourcing in the numerous mechanisms of inbound OI that managers can employ to encourage inbound knowledge flows across their organizational boundaries. That is why, in recent years, crowdsourcing has emerged as a promising OI strategy for firms searching for solutions to technical problems (Pollok et al. 2019a, b). In this perspective, our research aim is to understand how to frame crowdsourcing within the research stream of OI to bring out common critical issues and potentialities. To achieve this objective, this paper, true to the spirit of other reviews on the relationship between two topics (van der Vegt 2018), analyses how the interconnections between crowdsourcing and OI are depicted to map the current breadth and variation in the literature, to identify any major variations from previous findings and to contribute valuable insights into different aspects of both OI and crowdsourcing. Crowdsourcing highlights the growing importance of OI, especially as regards the need for developing certain mechanisms that will allow a smooth decision-making process, which will consist of examination, selection, and adoption of appropriate OI ideas, activities and projects (Alexy et al. 2012). In this context, as stressed out by Bogers et al. (2017), a better comprehension of the relationship between OI and crowdsourcing can lead to better understand the link between openness and firm performance and, in so doing, it contributes to the research in the innovation management field. There are several reviews about OI (West and Bogers 2014; Hossain et al. 2016); a literature review was also conducted from the knowledge management perspective (Natalicchio et al. 2017), and systematic studies on different aspects of OI, for example with a focus on SMEs (Galeano and Gaviria 2016; Hossain and Kauranen 2016) or on negotiation (Barchi and Greco 2018), on a specific industry (Secundo et al. 2019) or the organization and management of collaborative relationships (Perkmann and Walsh 2007) were carried out. Similarly, we can find several reviews, systematic mapping studies or taxonomies focused on crowdsourcing (Hossain and Kauranen 2015; Hosseini et al. 2015; Ghezzi et al. 2018), under different perspectives. Nevertheless, few OI studies use bibliometric analysis (Kovács et al. 2015; Randhawa et al. 2016) as well as, according to Liang and He (2017), few crowdsourcing studies are conducted from the bibliometric perspective. We believe that a joint review of the topics of crowdsourcing and OI is of interest to researchers and practitioners in the field of management. Indeed, there are several common themes: intermediation/brokerage and the role of intermediaries in OI and in crowdsourcing (Howells 2006; Feller et al. 2012; Silva and Ramos 2012); the selection process of the right external actors and involving them in an efficient way on one hand (Gürtler and Lindemann 2013), the solvers' intrinsic and extrinsic motivation to increase their participation in crowdsourcing sessions on the other (Körpeoglu and Cho 2018); rules and policies that should be adopted to manage Intellectual Property Rights (IPRs) in innovation contests (Mazzola et al. 2018) and in innovation ecosystems (Holgersson et al. 2018); the role of knowledge distance, seeker status and identity disclosure in the collaboration processes between heterogeneous agents (Pollok et al. 2019a); key success and unsuccess factors of crowdsourcing for innovation (Ramos et al. 2009; Lüttgens et al. 2014); the complex issues of value creation and value capture process of OI contests and crowdsourcing 
platforms (Poetz and Schreier 2012; Afuah andTucci 2013; Kohler 2015). Although these two topics share common themes and address similar managerial challenges from different points of view, as highlighted above, to the best of our knowledge, there is no systematic literature review have ever been carried out that dig deep into the intersection of both fields.

So, to fill in this gap, the main objective of this study is to carry out a comprehensive, systematic, and objective review of academic research to help shed light on the relationship between OI and crowdsourcing. With this purpose, we reviewed the literature published on these two topics applying bibliometric techniques, a type of review that has not been carried out to date in this context.

The rest of the paper is organized as follows. In the next section, we describe the methodology used in the systematic review process and the one used in the cocitation analysis and co-word analysis. The application of these complementary bibliometric methods enables a more robust, structured, and comprehensive review of OI and crowdsourcing research domains (Randhawa et al. 2016). The results of the process are explained in the third section: the findings thus present a clearer understanding of the intellectual streams and key concepts that underpin both OI and crowdsourcing. Then, the co-word analysis is used as a basis for a qualitative analysis of the main themes that emerged. Finally, we present and discuss the main results, proposing a reconceptualization of the thematic clusters, and the future outlook that can be drawn from our research.

\section{Method}

Following Keupp et al. (2012) approach, which recalls recent suggestions about a greater methodological rigor of reviews of the management literature (Tranfield et al. 2003; Pittaway et al. 2004), in our study we carried out a systematic literature review that provides co-citation and co-word analysis. Bibliometric studies, available in many fields, constitute a methodological innovation because, unlike traditional literature reviews, they are less subject to researchers' interpretations (MasTur et al. 2020). Using document titles, keywords, abstracts, or complete texts as the unit of analysis, it is possible to perform a co-word analysis to show the conceptual structure and the main concepts covered by the field of interest. We chose to apply this method to the author's keywords. The output of the co-word analysis is a network of themes and their relations that represent the conceptual space of a field; it differs from the co-citation analysis in that it systematically discovers concepts within the field and it enables a content-driven review of the literature (Zupic and Čater 2015).

Before we started the actual systematic review, we scanned and read some of the most salient articles in the field to determine the search terms. Then we used the Scopus database-updated to 23 January 2020 - to find all literature on the topic that could be of interest.

Our structured search strategy was as follows: < TITLE-ABS-KEY ("open innovation" OR "collaborat* innovation") AND TITLE-ABS-KEY (crowdsourc* OR "crowd-sourc*") AND (LIMIT-TO (LANGUAGE, "English"))> . 
We included the term "collaborat* innovation" because collaborative innovation is considered as a synonym of OI, and we wanted to reduce the probability to miss relevant literature due to a too limited search. We used the asterisks to retrieve results for similar versions and alterations of the terms, like crowdsourcing and crowd-sourcing or crowdsourced. The previous query allowed the retrieval of the 393 articles, all published since 2008. Then we applied clear exclusion criteria to be transparent in the selection process and limit the bias in selecting literature. So, the initial number of publications is assessed on their suitability of reflecting on both OI and crowdsourcing by scanning the title and abstract. In the first instance, the main reasons for elimination are irrelevant content or a different topic, such as crowdfunding or open source software; no relation to management or innovation issues, absence of abstract, no reference list (not eligible for co-citation analysis), erratum. A further 45 articles were excluded mainly based on the second screening of paper abstracts carried out through the parallel analysis of the abstracts by two researchers; in case of doubt, a convergent choice was reached. A schematic flow diagram outlining the whole literature selection process can be seen in Fig. 1.

Downstream of the selection process, we obtained 194 documents. These final publications form the knowledge base included in the co-citation and co-word analysis. Co-citation analysis (McCain 1990) uses co-citation counts to construct measures of similarity between documents, authors, or journals. Co-citation is defined as the frequency with which two units are cited together (Small 1973). A fundamental assumption of co-citation analysis is that the more two items are cited together, the more likely it is that their content is related (Zupic and Čater 2015). This way,

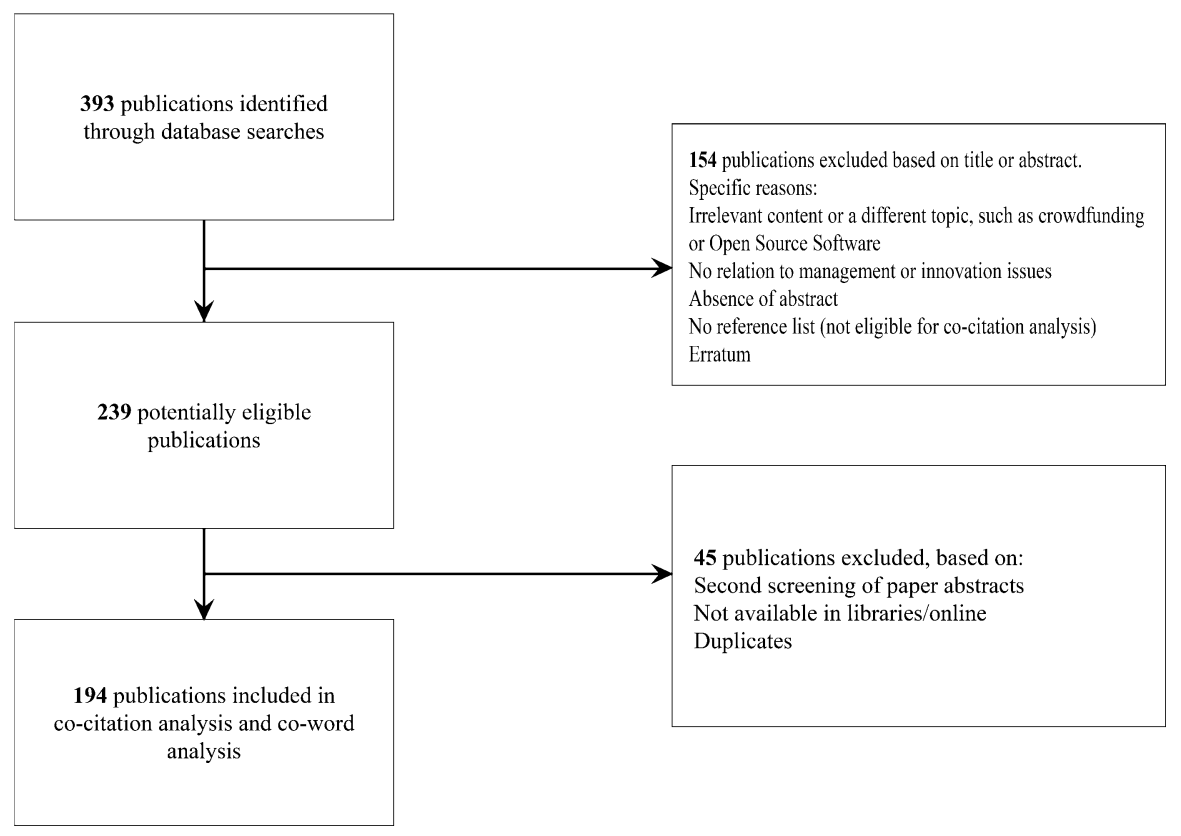

Fig. 1 Schematic depiction of the literature selection process 
this approach illustrates the structure and theoretical core of the investigated area. Co-word analysis (Callon et al. 1983) is a content analysis technique that uses the words in documents to establish relationships and build a conceptual structure of the domain. The idea behind this bibliometric technique is that when the frequency of co-occurrence of certain words in documents is high, the concepts underlying those words are closely related.

For executing the two types of bibliometric analyses on the data retrieved from Scopus as described above, we used the open-source software tool SciMAT version 1.1.04. SciMAT is a recent Science Mapping Analysis software tool developed by a research group at the University of Granada (Cobo et al. 2012).

\section{Knowledge base and evolution of crowdsourcing and open innovation}

Before proceeding with the actual bibliometric analysis, we examined the influence in the number of citations of the set of the selected papers. Citation is primarily a measure of impact, so the major ability of this kind of analysis is to find the documents, authors, and journals that are the most influential in a particular research stream (Zupic and Čater 2015). The table below (Table 1) shows the most-cited articles among the 194 articles under examination. Among the first articles in the list, there are several papers (Leimeister et al. 2009; Majchrzak and Malhotra 2013; Schlagwein and Bjørn-andersen 2014) published in Information Systems journals; this is not surprising since crowdsourcing has been studied by scholars and practitioners within several information systems disciplines (Ghezzi et al. 2018). Then we find Bogers et al. (2017), a joint work by several OI scholars. Scrolling through the list, the first article in which both themes explicitly appear is Seltzer and Mahmoudi

Table 1 Most cited documents

\begin{tabular}{lll}
\hline Rank & Citations & Articles \\
\hline 1 & 446 & Leimeister et al. (2009) \\
2 & 229 & Ebner et al. (2009) \\
3 & 193 & Majchrzak and Malhotra (2013) \\
4 & 166 & Bogers et al. (2017) \\
5 & 151 & Hutter et al. (2011) \\
6 & 126 & Seltzer and Mahmoudi (2013) \\
7 & 113 & Frey et al. (2011) \\
8 & 102 & Mergel and Desouza (2013) \\
9 & 98 & Bogers and West (2012) \\
10 & 85 & Marjanovic et al. (2012) \\
11 & 83 & Franke et al. (2013) \\
12 & 80 & Chiu et al. (2014) \\
13 & 79 & Chesbrough and Brunswicker (2014) \\
14 & 75 & Rouse (2010) \\
15 & 74 & Schlagwein and Bjørn-andersen (2014) \\
\hline
\end{tabular}


(2013) where crowdsourcing is described as a "key technique for OI, issuing a challenge to a large and diverse group in hopes of arriving at new solutions more robust than those found inside the organization". Other influential publications following in this list cover a variety of aspects including organizational learning with crowdsourcing (Schlagwein and Bjørn-andersen 2014), user innovation (Bogers and West 2012), the role of knowledge diversity in OI platforms (Frey et al. 2011), crowdsourcing based business models (Marjanovic et al. 2012).

To perform the co-citation analysis first we edited the set of documents, fixed misprints, misspelled authors' names, and other errors in titles, references, etc., to improve the quality of data. We also did the de-duplicating pre-processing. At the end of these operations, we moved from 9752 to 6282 references which are the ones we analyzed with SciMAT. Co-citation is applied to the cited articles; this way, it allows to identify the knowledge base, also referred to as the intellectual structure, of a topic (Zupic and Čater 2015).

Then we performed the time-slicing. At this stage, we grouped similar references and authors and we divided the time interval from 2008 to 2019 into three four-year subperiods: 2008-2011, 2012-2015, 2016-2019. Finally, we carried out the co-citation analysis with the following configuration: all the three subperiods, reference as the unit of analysis, a minimum frequency for data reduction of 2 and the network is built using co-occurrence relation (minimum co-occurrence set to 2). Other parameters were: equivalence index as the similarity measure to normalize the network, simple centers algorithm as the clustering algorithm with a maximum net size of thirty and a minimum of five, core mapper for the document mapper, h-index as the quality measures, and, lastly, inclusion index for the evolution map and equivalence index for the overlapping map. It is useful to remind that the co-citation analysis is performed on the references of the selected documents, so there may be overlaps or not. The co-citation analysis is useful to uncover the key references in a research field (Cobo et al. 2012) and to trace its intellectual roots. By applying the simple centers algorithm, the clustering process locates reference networks that are strongly linked to each other. To visualize the result, we used SciMAT to create an evolution map, which detects the evolution areas across the defined subperiods. The evolution map is displayed in Fig. 2. The spheres represent the clusters, and their volume is proportional to the number of documents. The characteristics of the line define the quality of their relations, representing the weight of the "evolution nexus" between the items of two consecutive periods. More precisely, the solid line means that the linked clusters share the main item (usually the most significant one), whereas the dotted line means that the themes share elements that are not the main item, describing elements that are relatively far from the main ones (Alcaide-Muñoz et al. 2017). The thickness of the edges is proportional to the inclusion index, reflecting the proportion of the number of published documents in each cluster (Cobo et al. 2012; López-Robles et al. 2018).

The map shows the presence of some milestones, like "The era of Open Innovation" (2003), Chesbrough's seminal article, von Hippel (2005) and Surowiecki's book (Surowiecki 2005), that have many links to the papers of the following subperiod. Moreover, we can observe that this central role is inherited by Brabham (2008), Brabham (2010), von Hippel (2005) and Boudreau et al. (2011); we also 


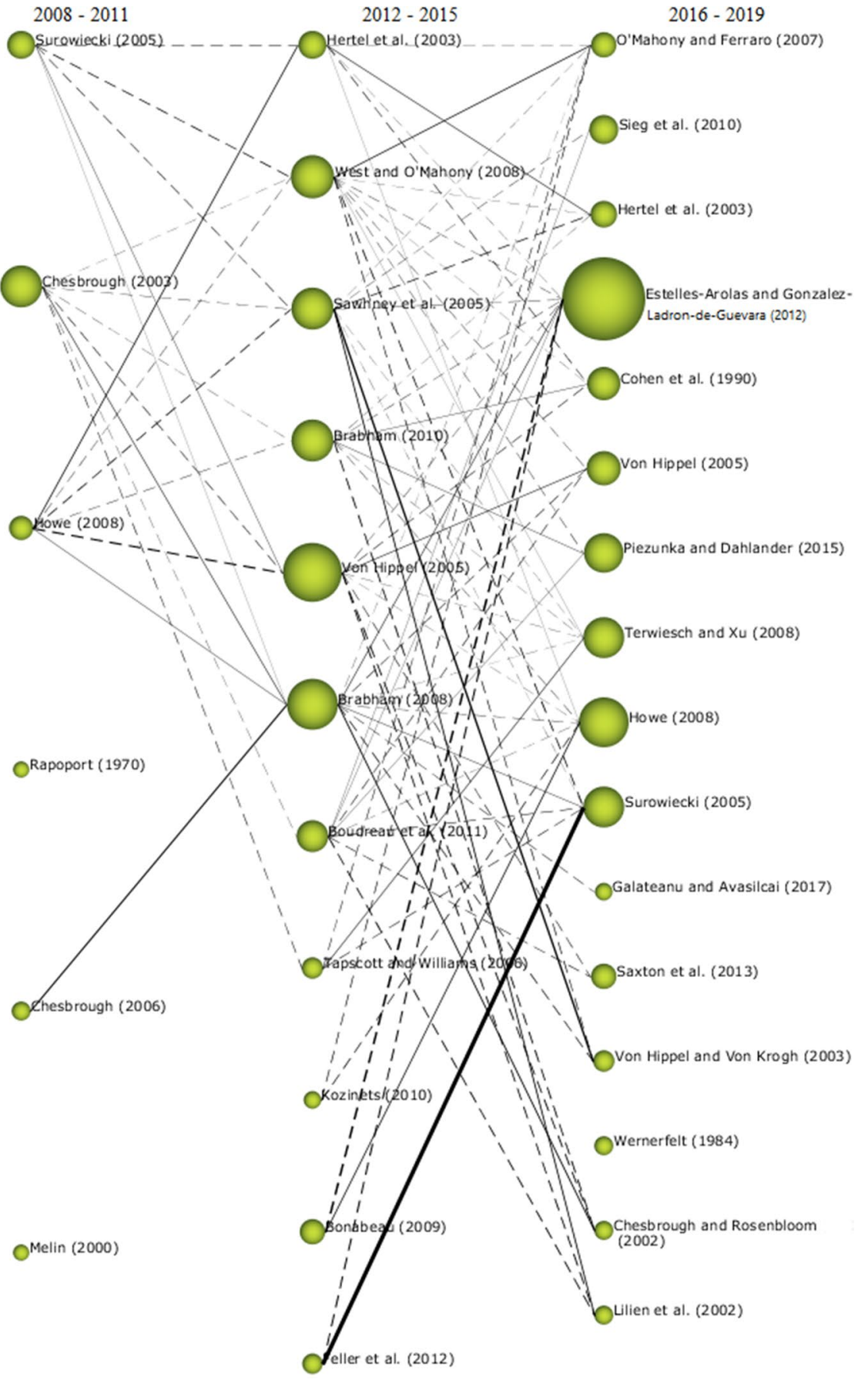

Poole and Van de Ven (1989)

Fig. 2 Evolution map-Source: SciMAT- Own Elaboration 
find some historical roots in similar domains like open-source, with the paper by Hertel et al. (2003) and West and O'mahony (2008), and co-creation (Sawhney et al. 2005). Another relevant paper is Feller et al. (2012), which investigate managerial and organizational aspects, such as how to orchestrate a sustainable model of crowdsourcing, that anticipated promising lines of research in this area. In the last subperiod, one of the most important publications is the article written by Estellés-Arolas and González-Ladrón-de-Guevara (2012) that provides a wide definition that covers the majority of existing crowdsourcing processes, but it does not clarify the relationship with other related concepts such as Outsourcing, Open Source, OI.

It is interesting to note the evolution during the three subperiods of the relevance of the papers also using the strategic diagram. This visualization technique shows the detected clusters of each period in 2-dimensional space, according to their centrality and density rank values (since we used median for classifying clusters for better legibility) along the abscissa (centrality) and the ordinate (density) (Cobo et al. 2011, 2012). As defined by Callon et al. (1991), centrality measures for a given cluster the intensity of its links with other clusters, in other words, it measures the degree of interaction of a network with other networks, whereas density measures the internal strength of the network, characterizing the strength of the links that tie the words making up the cluster together. Following Callon et al. (1991), given both measures it is possible to identify four groups: in the first quadrant (upper right) we find the clusters known as motor clusters since they present strong centrality and high density (Cobo et al. 2018); in the second (lower right corner) basic and transversal clusters; in the quadrant three (upper left corner) the highly developed but isolated and peripheral clusters, that are specialized but marginal; finally, the fourth quadrant (lower left) shows the emerging or declining clusters, characterized by low density and low centrality. Surprisingly, we find that in the first period 2008-2011 (Fig. 3) a central role is played by a non-scientific publication, the book "The Wisdom of Crowds" by Surowiecki (2005), that examines why the many are smarter than the few and the impact of collective wisdom on business, economies, societies, and nations, meanwhile, less surprisingly, Chesbrough's seminal work "The Era of Open Innovation" (Chesbrough, 2003a, b) is a basic and transversal element.

Similarly, in the successive quadrennium 2012-2015, we can observe an increased number of motor clusters, due to a growing number of co-citations that have accumulated over time (Fig. 4). These include the following papers: West and O'mahony (2008), Brabham (2010), Hertel et al. (2003), and Sawhney et al. (2005).

Finally, in the last diagram (Fig. 5), we can observe evolution in terms of the number of the more significant publications in the field. Among the motor clusters, some papers bring attention to communities and their governance (O'Mahony and Ferraro 2007), others deal with the managerial challenges faced by companies working with both OI and crowdsourcing intermediaries (Sieg et al. 2010; Piezunka and Dahlander 2015). We find also the work by Estellés-Arolas and González-Ladrón-deGuevara (2012), in which an exhaustive and consistent definition for crowdsourcing is presented. For our purposes, the position of this paper is very interesting, because the authors affirm that "another area where consensus does not exist is in the relationship between crowdsourcing and other associated concepts such as OI". Among the emerging clusters, we want to underline the presence of a recent "taxonomy 


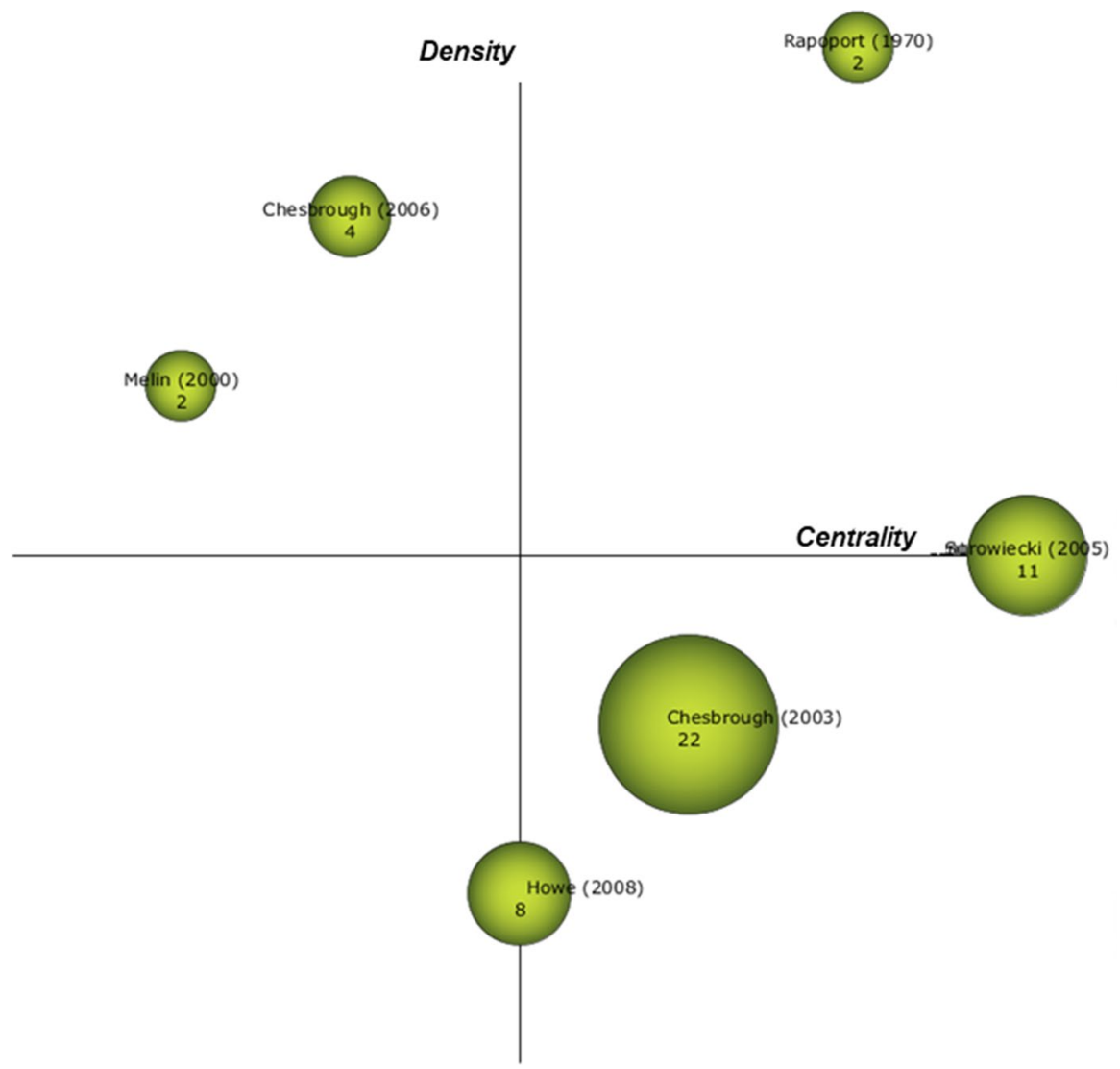

Fig. 3 Strategic diagram 1-period 2008-2011. Source: SciMAT - Own Elaboration. See Appendix A for figure legend

theory" of crowdsourcing, in which the crowdsourcing model has been described from the perspective of a virtual production platform (Saxton et al. 2013), together with previous papers that, although they do not directly concern crowdsourcing or OI, provide a theoretical basis for them, as they face common challenges and issues. We find for instance the performance assessment of innovative and novel methods compared to traditional idea generation techniques (Lilien et al. 2002), issues from the organizational point of view emerged in the context of Open Source (Von Hippel and Von Krogh 2003), the exploration of the role of business models to capture value from innovation (Chesbrough and Rosenbloom, 2002). Consistently with their theoretical importance, we find in the second quadrant among the basic and transversal themes, Cohen and Levinthal (1990), Surowiecki (2005), and Howe (2008). Finally, in the fourth quadrant, Galateanu and Avasilcai (2017) and Poole and van de Ven (1989) is very isolated, while Terwiesch and Xu (2008) has a high centrality and a greater number of links with other clusters, as can be seen on the evolution map (Fig. 2). In summary, our results show that many authors from different 


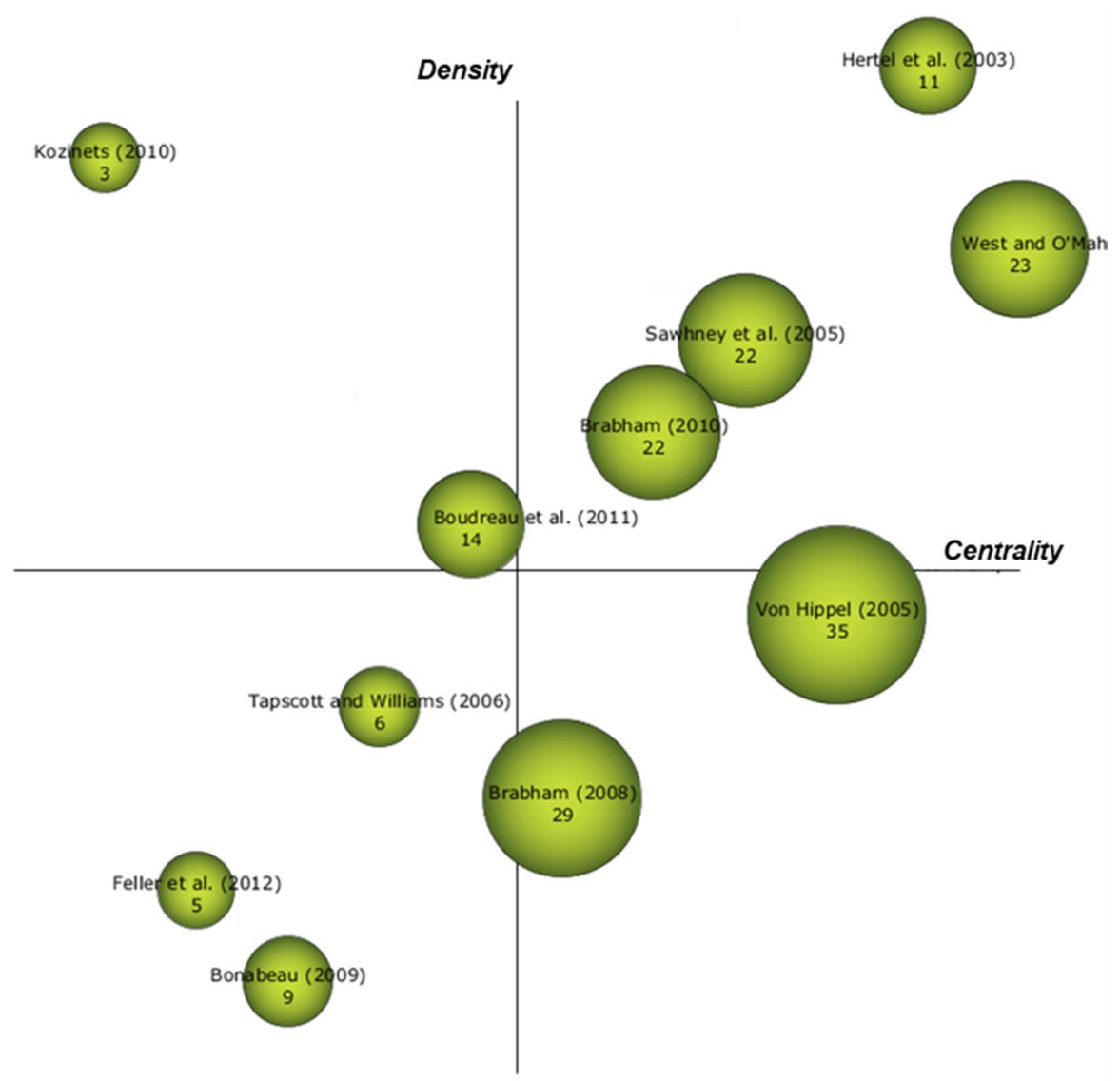

Fig. 4 Strategic diagram 2-period 2012-2015. Source: SciMAT - Own Elaboration. See Appendix B for reference details

disciplines have contributed to the literature, that this is a field in which interest has grown over time, and that there is no single discipline covering all aspects. In the next paragraph, starting from the results of the co-word analysis, we will deal with a more detailed and in-depth discussion and interpretation of the common themes.

\section{Content analysis: emerging themes, trending topics, and shared areas of application}

Similar to what was done in the previous co-citation analysis, as a first step, we did a deduplication process, grouping similar words (by plurals) or those words that represent the same concept, looking for synonyms or duplicates in words with the highest number of documents and repetitions. Finally, as usual in these cases (Cobo et al. 2014), some meaningless keywords in this specific context, for example, words with 




Fig. 5 Strategic diagram 3-period 2016 - 2019. Source: SciMAT - Own Elaboration. See Appendix C for reference details

a broad and general meaning as RESEARCH-AGENDA, PRIORITY-JOURNAL, were considered in the same manner as to stop words.

To perform the co-word analysis, the following configuration in SciMAT was established: word as the unit of analysis, co-occurrence analysis as the tool to build the networks, association strength as the similarity measure to normalize the networks, and the simple centers algorithm as the clustering algorithm to detect the clusters or themes (Cobo et al. 2014; Lubicz 2017; López-Robles et al. 2018; Santana and Lopez-Cabrales 2019). We chose to use the association strength as a normalization measure because, according to van Eck and Waltman (2009), "co-occurrence data can best be normalized using a probabilistic measure like association strength and this provides strong support for the use of the association strength in scientometric research". Other configurations were core mapper for the document mapper, inclusion index for the evolution map, and equivalence index for the overlapping map. By running the co-word analysis through SciMAT, 10 different clusters were distinguished, as reported in the following table (Table 2). 
Table 2 The ten clusters identified

Name

coreDocuments

(documents-

Count)

\begin{tabular}{ll}
\hline Open-innovation & 37 \\
Crowdsourcing & 36 \\
Platforms & 25 \\
Innovation & 23 \\
Product-development & 16 \\
Information-management & 14 \\
Web & 13 \\
Data & 8 \\
Human & 7 \\
Collaboration & 6 \\
\hline
\end{tabular}

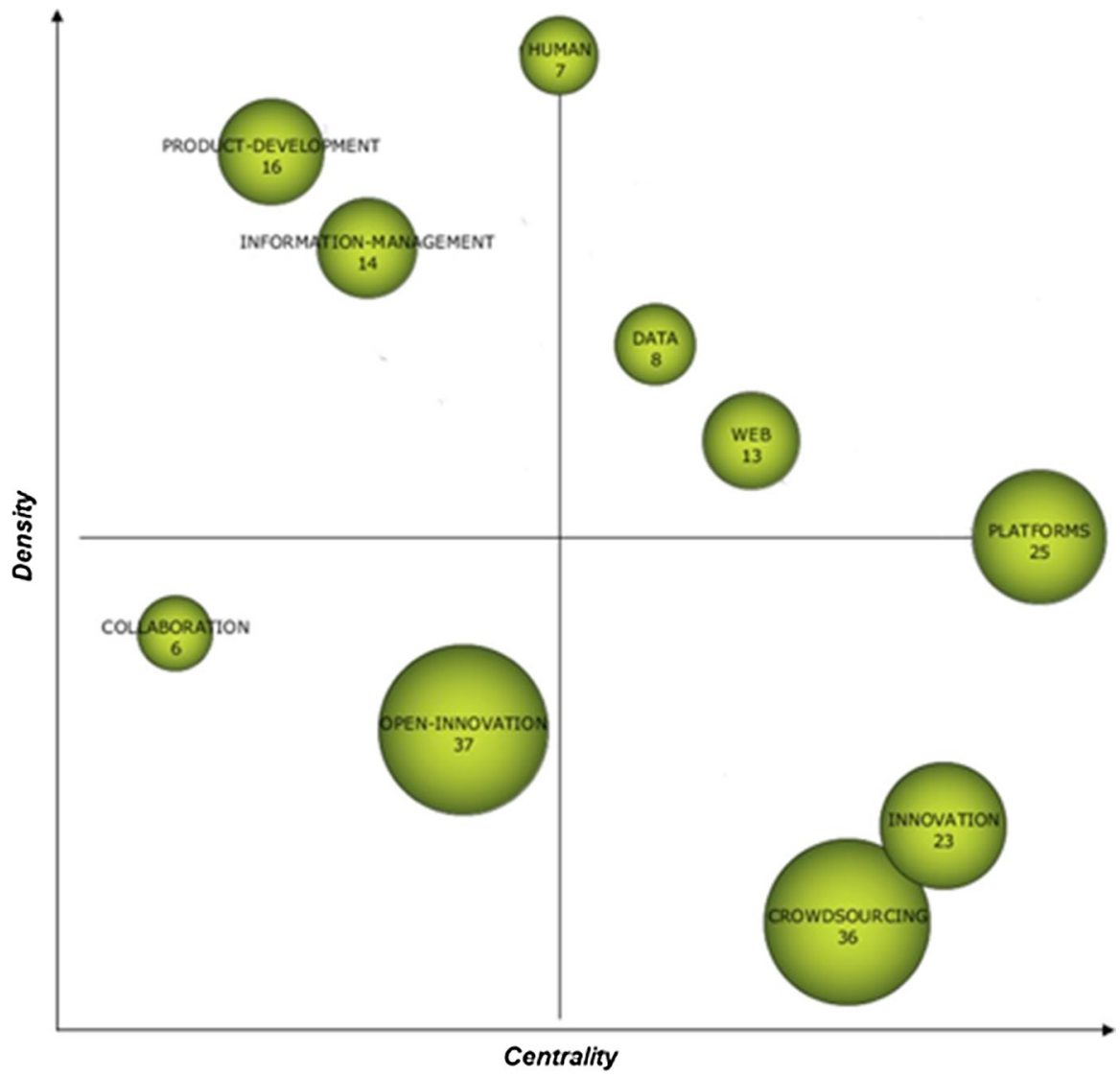

Fig. 6 Strategic diagram, period 2008-2019. Source: SciMAT- Own Elaboration 
The detected themes and the relative clusters' information are visualized utilizing the strategic diagram (Fig. 6). As already pointed out, this diagram allows to visualized a research field as a set of research themes (Cobo et al. 2018), mapped along two axes (centrality on the abscissa and density on the ordinate); as centrality grows, the importance of external ties concerning the other themes grows, and the greater the density, the better the internal ties among the themes are developed.

In the strategic diagram, Human and Platforms are characterized by the maximum value of density and centrality, respectively. Among the motor-themes we find Web and Data; in the upper and left quadrant, the specialized themes are Product Development and Information Management, among the basic and transversal themes we find Crowdsourcing and Innovation, while Open Innovation and Collaboration are located in the lower-left quadrant.

In addition to the strategic diagram, we also show and analyze all ten thematic networks identified. According to Cobo et al. (2011), a thematic network is a visualization instrument available on SciMAT that allows the representation of the network graph created by the keywords (nodes) in a research theme and their internal links (edges); the most central keyword in the related theme is used to designate each thematic network (Santana and Lopez-Cabrales 2019). In this kind of graph, the thickness of the edge between two nodes is proportional to the selected similarity measure.

It is also worth noting that the presence among the resulting clusters of two clusters corresponding with the two terms under investigation is not surprising as in the initial query for data fetching the key terms Open Innovation and crowdsourcing were expressly mentioned. We recall that the co-word analysis was conducted on the keywords associated with the papers collected and that the clusters listed in Table 2 are not simply the words with the most occurrence, but thematic networks where the most central word is used as a label.

The next subsections entail a description of each cluster, starting from the one with the highest value of the performance indicator (number of core documents) proceeding in descending order.

\subsection{Cluster 1: open innovation}

This important cluster coincides with one of the key terms of this literature review. Within this thematic network, in addition to the Open innovation, we find eleven keywords, as in Fig. 7.

By examining the thematic network, we can identify some keywords corresponding to research lines of great interest to the scholars in this field. Among these, we note a certain interest in theoretical contributions such as the link between OI and Absorptive capacity, defined as a "firm's ability to recognize the value of new information, assimilate it, and apply it to commercial ends" by Cohen and Levinthal (1990). As argued by Vanhaverbeke et al. (2008), OI is not possible without absorptive capacity as an internal capability of innovating companies. Both OI and absorptive capacity focus on the sourcing of externally developed knowledge. We then find different contributions on possible approaches to leveraging External Knowledge 


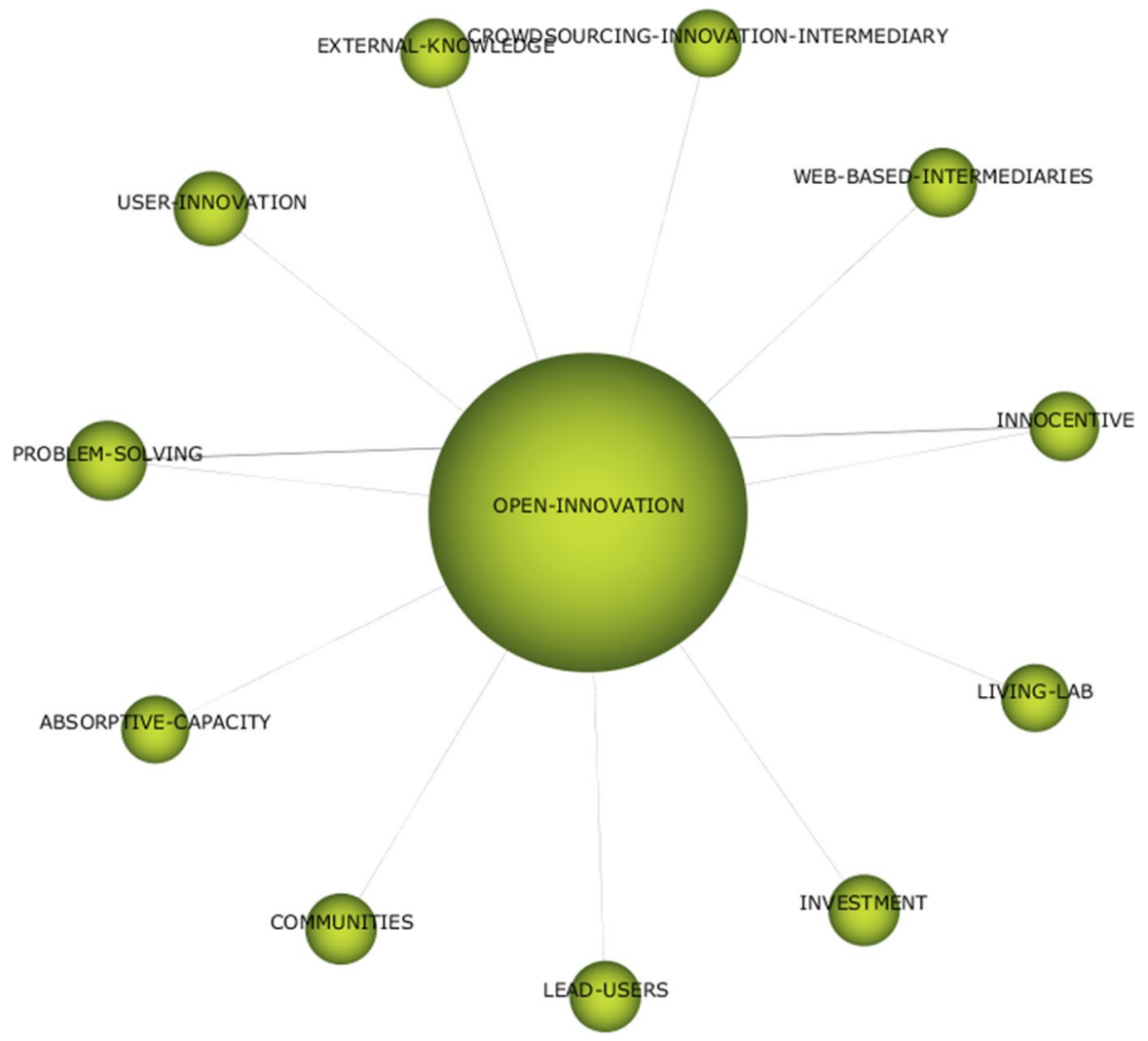

Fig. 7 Cluster's network Open Innovation- Source: SciMAT- Own Elaboration

and engaging with external parties, such as Living Lab, third-party OI intermediaries, usually Web-based platforms or Crowdsourcing innovation intermediaries, Communities. One of the most investigated OI platforms is InnoCentive, whose business model is centered on opening up the search process and broadcasting science problem information to outsider solvers (Boudreau and Lakhani 2009). We can notice that in the network there is a direct link between InnoCentive and Problem Solving. We also note that related topics such as User Innovation and Lead Users appear.

\subsection{Cluster 2: crowdsourcing}

Another important cluster that coincides with the other key term of this literature review is represented by the keyword Crowdsourcing, as illustrated in Fig. 8.

Analyzing this thematic network, it is possible to recognize research lines related to the three different actors involved in the process: the problem's owner (a firm or an organization), the intermediary, and the crowd. Strategic planning, Profitability, and Design problems concerns to problem's owners. They relate to the need to make 


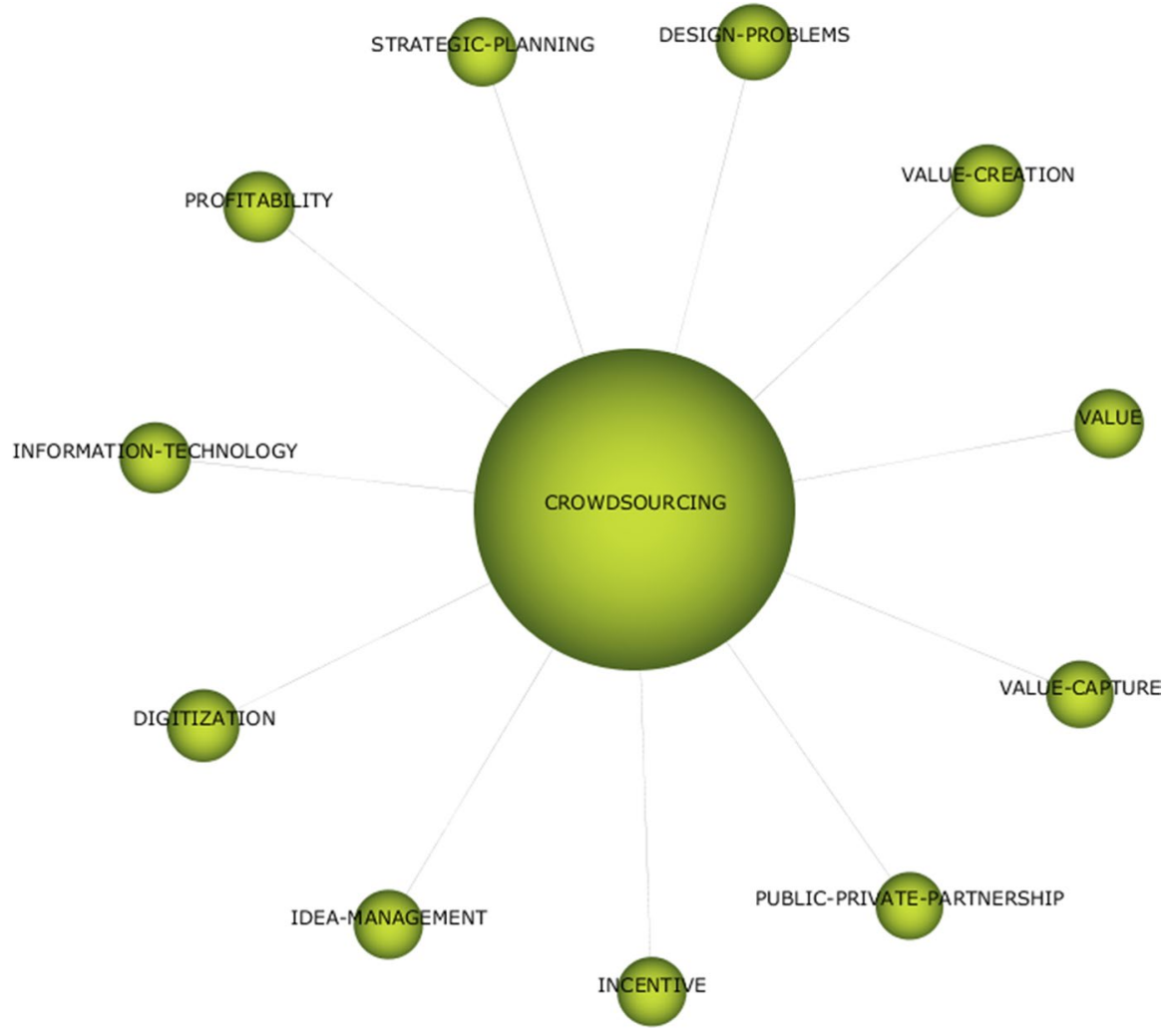

Fig. 8 Cluster's network Crowdsourcing - Source: SciMAT- Own Elaboration

Strategic planning alleviate risks and maximize Profitability, outsourcing tasks and problems to a crowd of potential solvers; also, one of the biggest problem for seekers - especially SMEs - is how to find the useful and valuable and less costing innovative design about their product (Lee 2016). Information technology, Digitization, and Idea Management are more pertinent to intermediaries, as they affect the technology implementation and management of the process to mediate access to the crowd of innovation and solution providers. From the crowd's point of view, Incentive is one of the dimensions that characterized the crowdsourcing process (Ali-Hassan and Allam 2016). Together with motivation and engagement, Incentive is one of the critical success factors of this mechanism. It also emerges the relevance that the concept of Value has had and still has in the expert literature: the attention is focused on the whole chain starting from the Value creation to its Capture and final appropriation. 


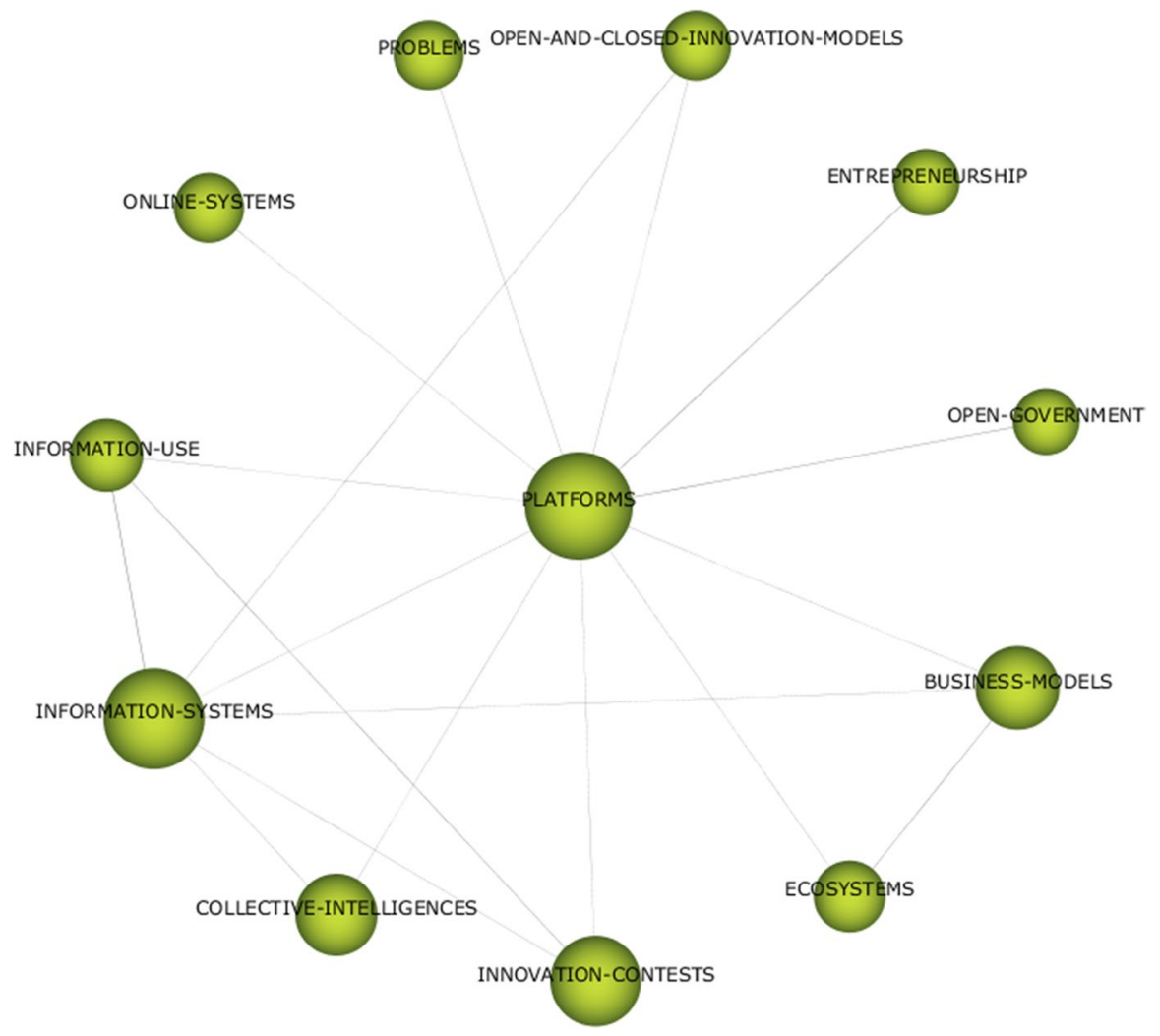

Fig. 9 Cluster's network Platforms- Source: SciMAT-Own Elaboration

\subsection{Cluster 3: platforms}

This cluster (Fig. 9), placed between the second and the third quadrant, is the one where the central keyword is Platforms.

This theme covers research lines such as Business models, Innovation contests, Online Systems, Ecosystems, Problems, Open Government, Collective Intelligence, among others.

In the extant literature, we found that the Platforms have been subject to many studies regarding the Business Model (Afuah 2014; Kohler and Nickel 2017; Kohler 2018), the features of the Online systems, the mechanisms underlying the implementation of Innovation contests. The platforms represent an effective and enabling tool to implement OI strategies, to realize product and service innovation (Xu et al. 2012), and to exploit Collective Intelligence to gain and develop new ideas for products and services and to generate new knowledge (Buecheler et al. 2010).

From the scholars' perspective, they raise interesting questions about the Problems they host, the Information use, and IPR management (Fantoni et al. 2016; Mazzola et al. 2018). According to Bogers et al. (2017), the Platforms are an 
actual form of Ecosystems and by this nature, are intrinsically linked to other concepts like Entrepreneurship. Schenk et al. (2019) discussed the conditionssuch as the presence of network externalities, transaction costs, and skill requirements - under which the use of a third-party platform may be considered more appropriate than a proprietary platform, while Jayakumar (2016), relying on a real case study - the crowdsourcing intermediary Talenthouse India-reviewed the differences between Closed and Open Innovation Models highlighting the added value of this kind of marketplaces for the exchange of knowledge between communities and their client firms.

The platforms can also facilitate web-based interaction between governments and citizens enabling their participation process in public planning (Brabham 2009) and leading to forms of Open government, like, for instance, the co-production of public services (Moon 2018) or the involvement of citizens in crowdsourced and peer-produced solutions to public management problems (Mergel 2015).

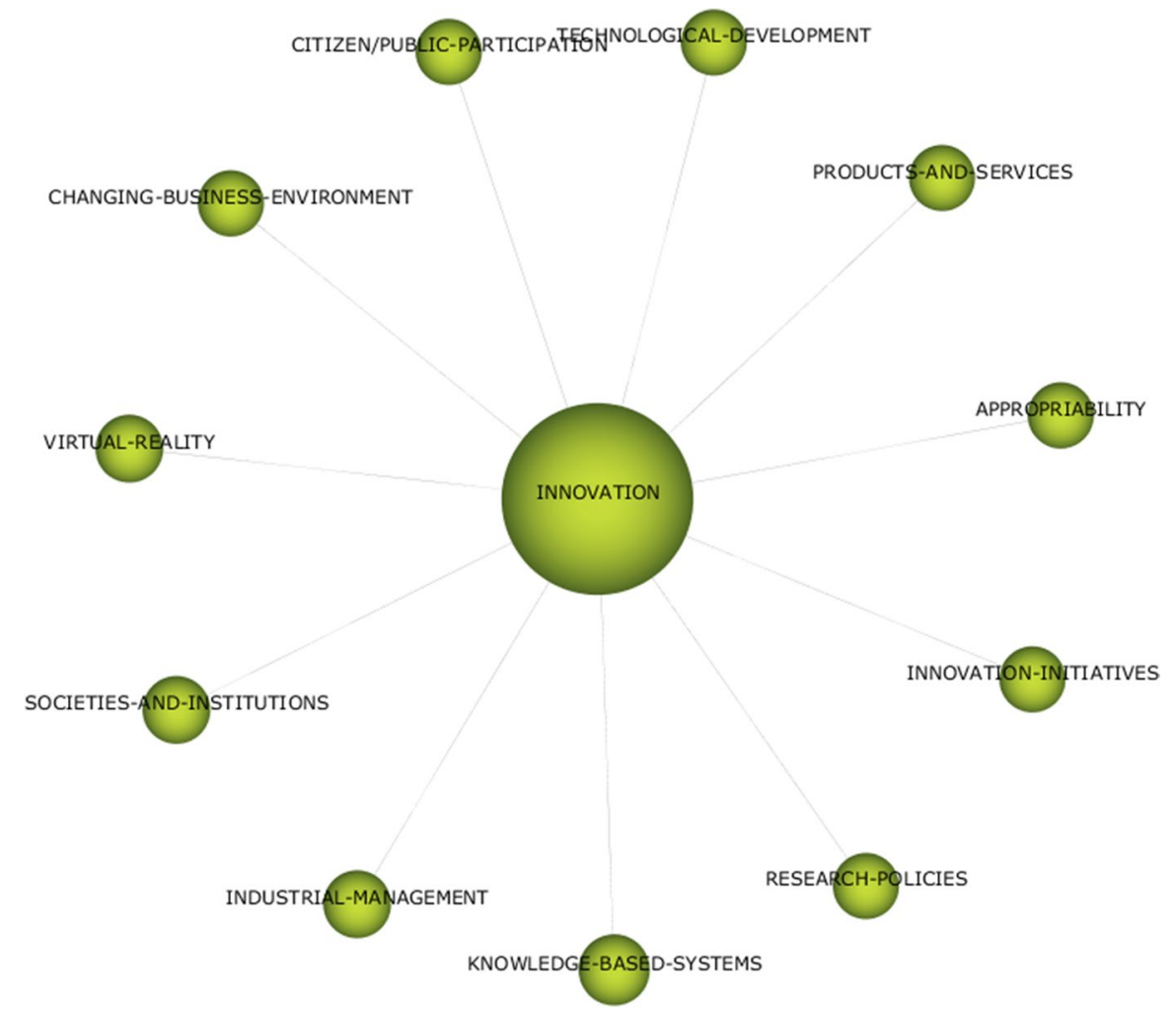

Fig. 10 Cluster's network Innovation-Source: SciMAT-Own Elaboration 


\subsection{Cluster 4: innovation}

Analyzing this cluster (Fig. 10), interest in the type of actors involved in the innovation process emerges (Societies and institutions, Citizen/Public participation), along with interest in appropriate, mature, and far-sighted Research Policies to allow wider participation in research and innovation activities that involve citizens. According to Seltzer and Mahmoudi (2013), Citizen participation, like OI-despite objectives and requirements not always perfectly aligned-seeks involvement on the part of users, customers, and "thinkers' as a means for augmenting the perspectives found inside the firm or organization.

In this context, the appearance of the concept of Changing business environment deserves special attention. In the last decade, the innovative processes of companies have undergone profound developments due to several reasons. Therefore, to respond to the new challenges proposed by the market and to foster Technological development, they have begun to develop dynamics of OI (Chesbrough, 2003a, b) affiliated by a growing propensity to carry out collaborations for innovation with external sources of knowledge and expertise, and the implementation of specific Innovation initiatives. Also, Industrial management, which is about optimally producing products and services mostly deploying people as an asset for the entire organization, can benefit from the involvement of external communities via online platforms. The presence of the keyword Virtual Reality is motivated by the fact that is a trending topic and a buzzword for what concerns the last technological development just mentioned. Another important element of this cluster is the theme of Appropriability. Appropriability together with knowledge mobility and stability is one of the necessary processes to 'orchestrate' crowdsourcing to ensure success and satisfaction for both innovation providers and innovation seekers (Feller et al. 2012).

\subsection{Cluster 5: Product-development}

This network (Fig. 11) presents a great number of internal links, as confirmed by its positioning at a high-density level in the strategic diagram.

Examining the cluster, a trend already studied (Poetz and Schreier 2012; Schemmann et al. 2016) is confirmed: in the last years, since crowdsourcing for New Product Development has become very popular among firms in different industries, such as Manufacturing and Creative industries. As we have already noticed, the adoption of the OI paradigm can help the reduction of Research and Development costs, the sharing of the risks of innovation, and, in some cases, the increase of the speed at which new Innovative products and services are brought to the market. Moreover, crowdsourcing is one of the tenants of Social product development, a new approach to design whose purpose is to "improve traditional distributed and collaborative design processes" by enhancing "communication and collaboration (...) through social computing techniques" (Schaefer and Forbes 2019). Many sectors can benefit from approaches where the drivers of Decision-Making are Customer Engagement and Satisfaction. Several authors (Brabham 2008; Kohler and Nickel 2017; 


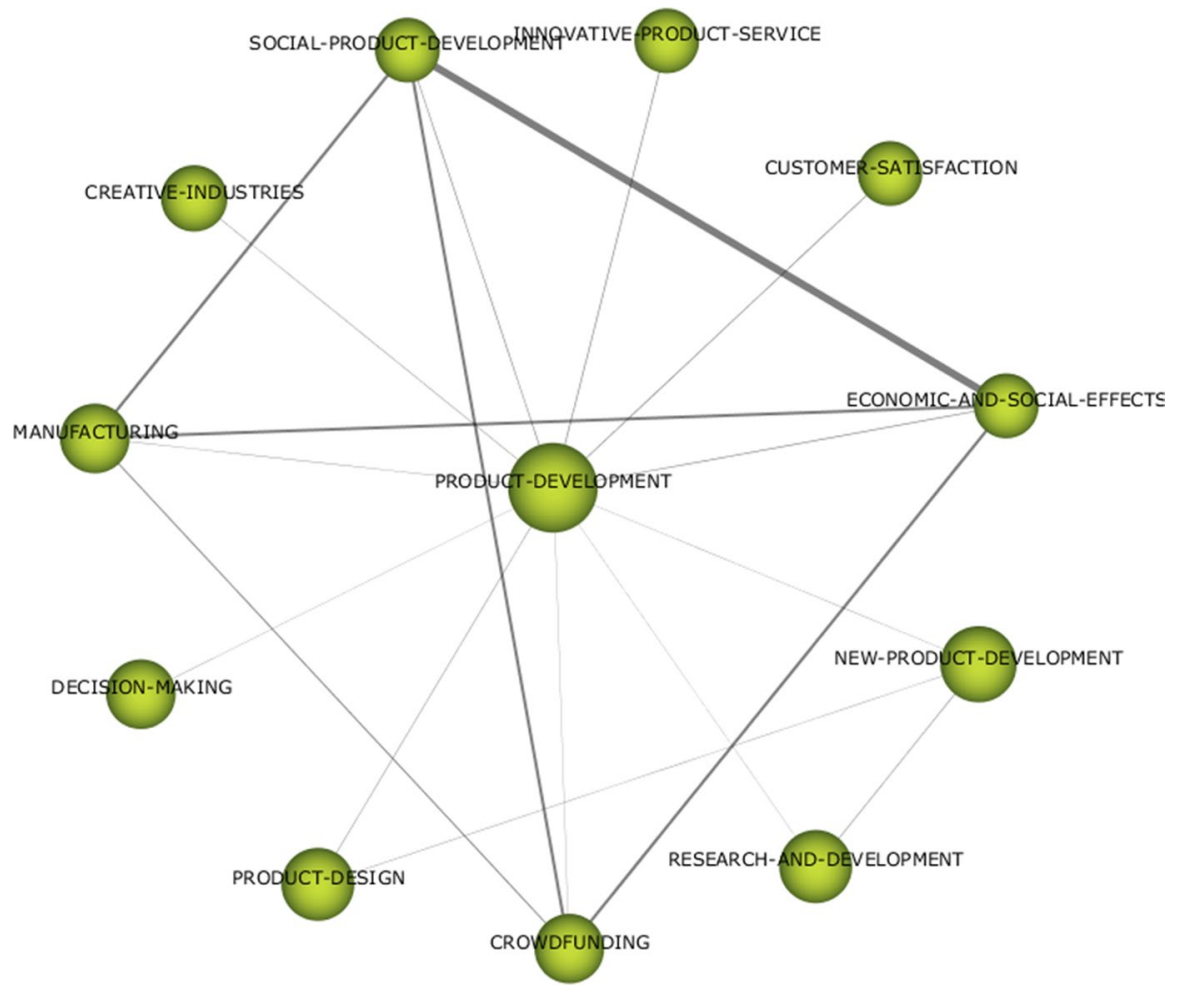

Fig. 11 Cluster's network Product Development— Source: SciMAT

Avasilcai and Bujor 2018) have proposed the Threadless platform as a case study in Creative Industries where the OI process is successfully applied to the design stage of product development (Product design). The twelfth element of the cluster is Crowdfunding. For our purposes, we knowingly decided to exclude the term Crowdfunding from the initial query because, despite various affinities, it represents a distinct search domain. It is not surprising, however, to find this word in this thematic cluster as crowdfunding platforms often stimulate a collaborative process of a group of people who use their money together to support the development of new products from below, thus causing Economic and social dynamics and effects. We can, therefore, infer that various steps of product development, from concept generation to design, even to financial support in the realization, can benefit from a crowd-based approach.

\subsection{Cluster 6: information management}

The fulcrum of this thematic network (Fig. 12) is Information management, which concerns the process of collecting, storing, managing, and maintaining information. 


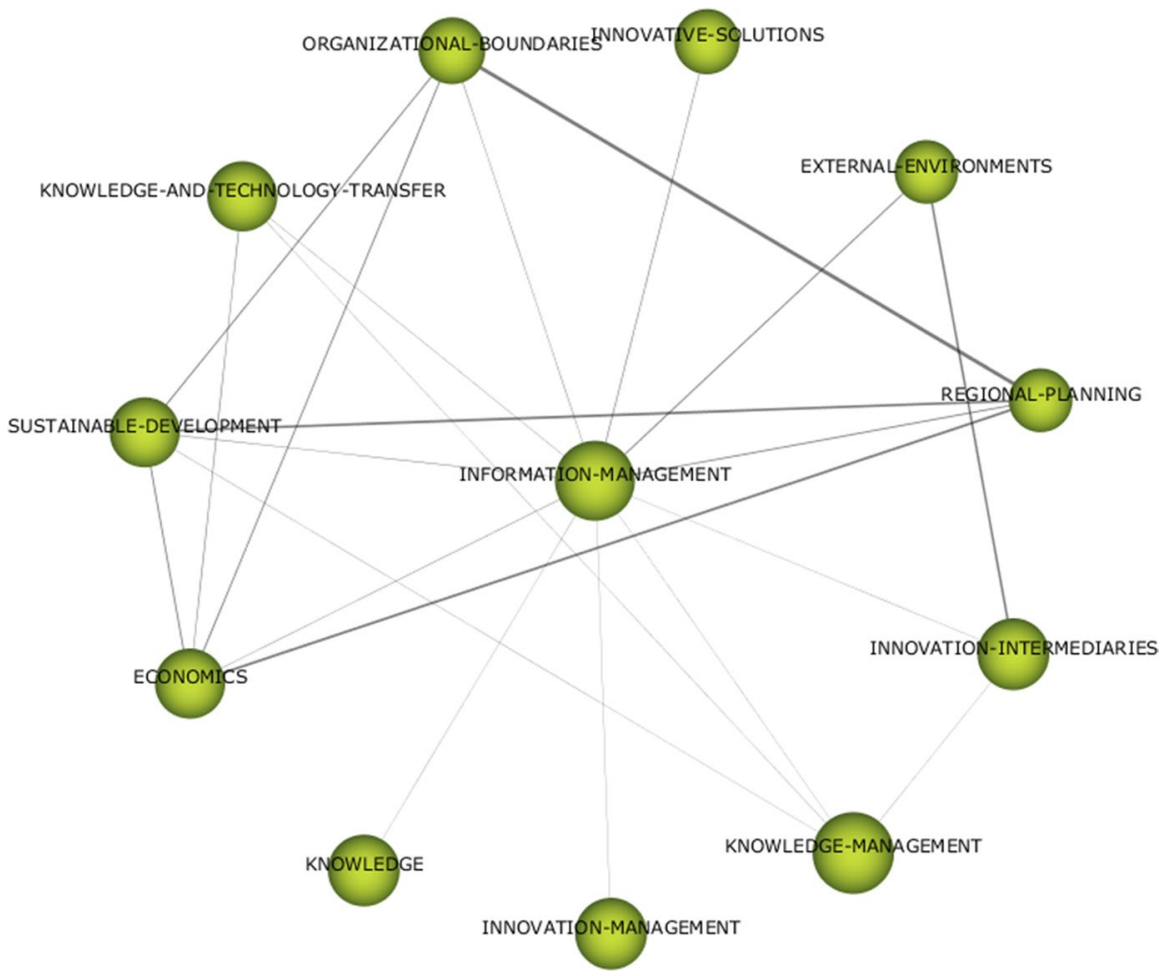

Fig. 12 Cluster's network Information Management- Source: SciMAT- Own Elaboration

In addition, we find themes such as Knowledge Management, Knowledge and Technology Transfer, Innovative solutions, Sustainable Development, among others.

Usually, Information management is achieved through a purpose-built technological architecture that is the link between the internal processes and the External environment (de Mattos et al. 2018). This has a significant impact also on Knowledge Management inside and outside the Organizational boundaries. In fact, according to Dimitrova and Scarso (2017), crowdsourcing, on one side, is moving the attention of Knowledge Management toward the organizations' external environment as a significant knowledge source; on the other, it is shifting the focus of knowledge management towards knowledge creation/acquisition activities, instead of towards the knowledge transfer process. Several authors (Feller et al. 2012; Silva and Ramos 2012; De Silva et al. 2018) stressed the role played here by Innovation intermediaries. According to these authors, Innovation Intermediaries facilitate the whole Innovation process, enabling innovation exchanges between organizations and crowds, covering knowledge search, problem-solving, and connecting and coordinating Knowledge and Technology Transfer between actors. They, therefore, act as knowledge repositories, making knowledge-based contributions when providing Innovative solutions to their clients. 


\subsection{Cluster 7: web}

This thematic network (Fig. 13) includes different topics, such as Social networking, Co-innovation, Knowledge sharing, Idea competition, Online Communities, to name a few. As stressed by several authors, the outbreak of Web 2.0 technologies, including Social networking, has led to their use in many domains of business for Knowledge sharing, Co-innovation as well as customer engagement. These technologies have also allowed the overcoming of geographical barriers to the Broadcast search to provide Solutions to specific problems, becoming, thanks to the potential of the Web, fundamental tools to realize initiatives of opening and sharing. Some publications, especially in the Information Systems field, have focused on the classification of crowdsourcing initiatives, campaigns, and Idea competitions to characterized peculiarities and clarify how crowdsourcing differs from Outsourcing and Open Source (Marjanovic et al. 2012), meanwhile, other studies, usually starting from real Case studies, concentrated on the Taxonomies of the crowdsourcing process, analyzing the different parts of this process and their associated metrics. Recently, Piazza et al. (2019) stressed the importance of an appropriate governance structure of the

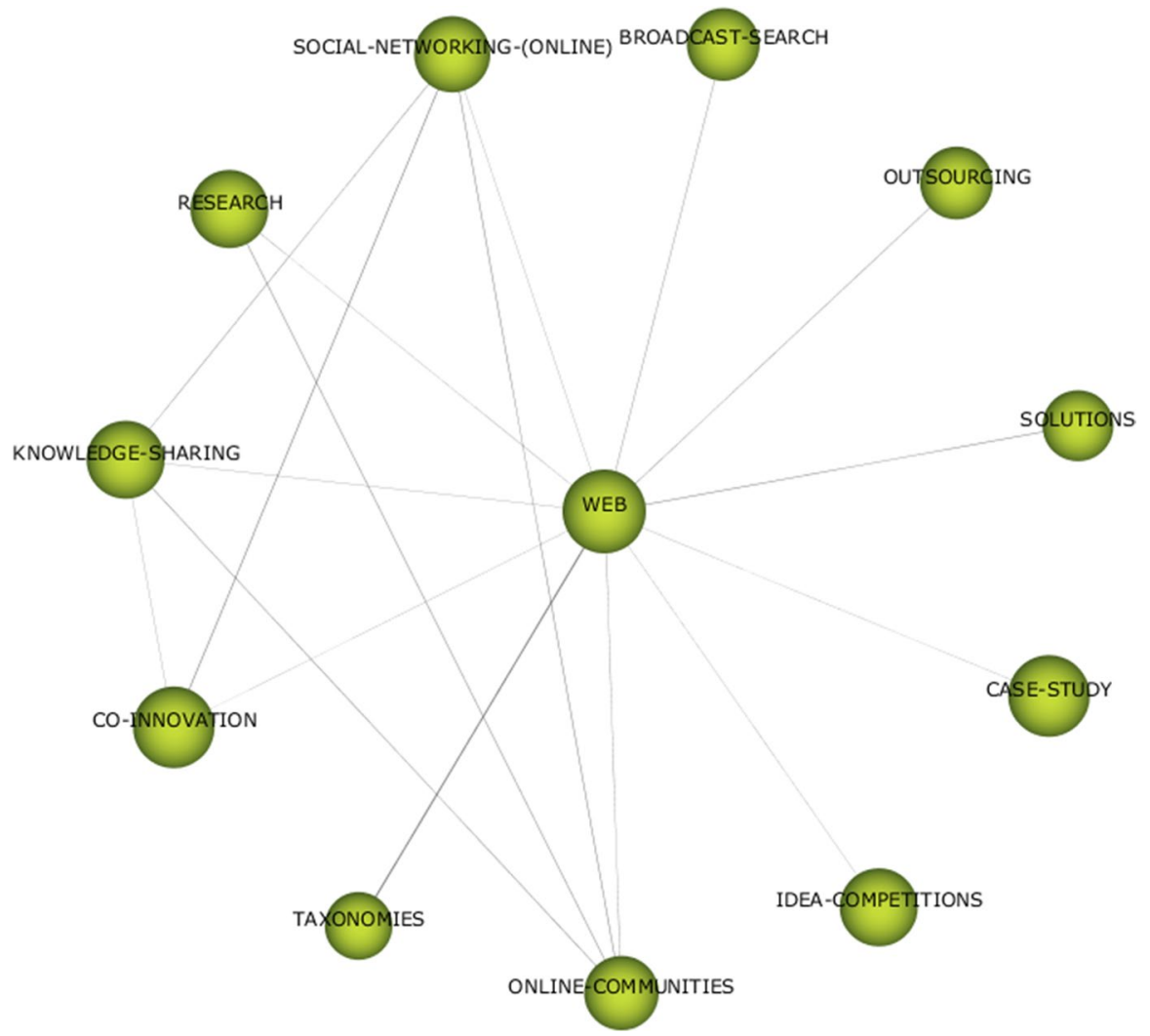

Fig. 13 Cluster's network Web-Source SciMAT-Own Elaboration 


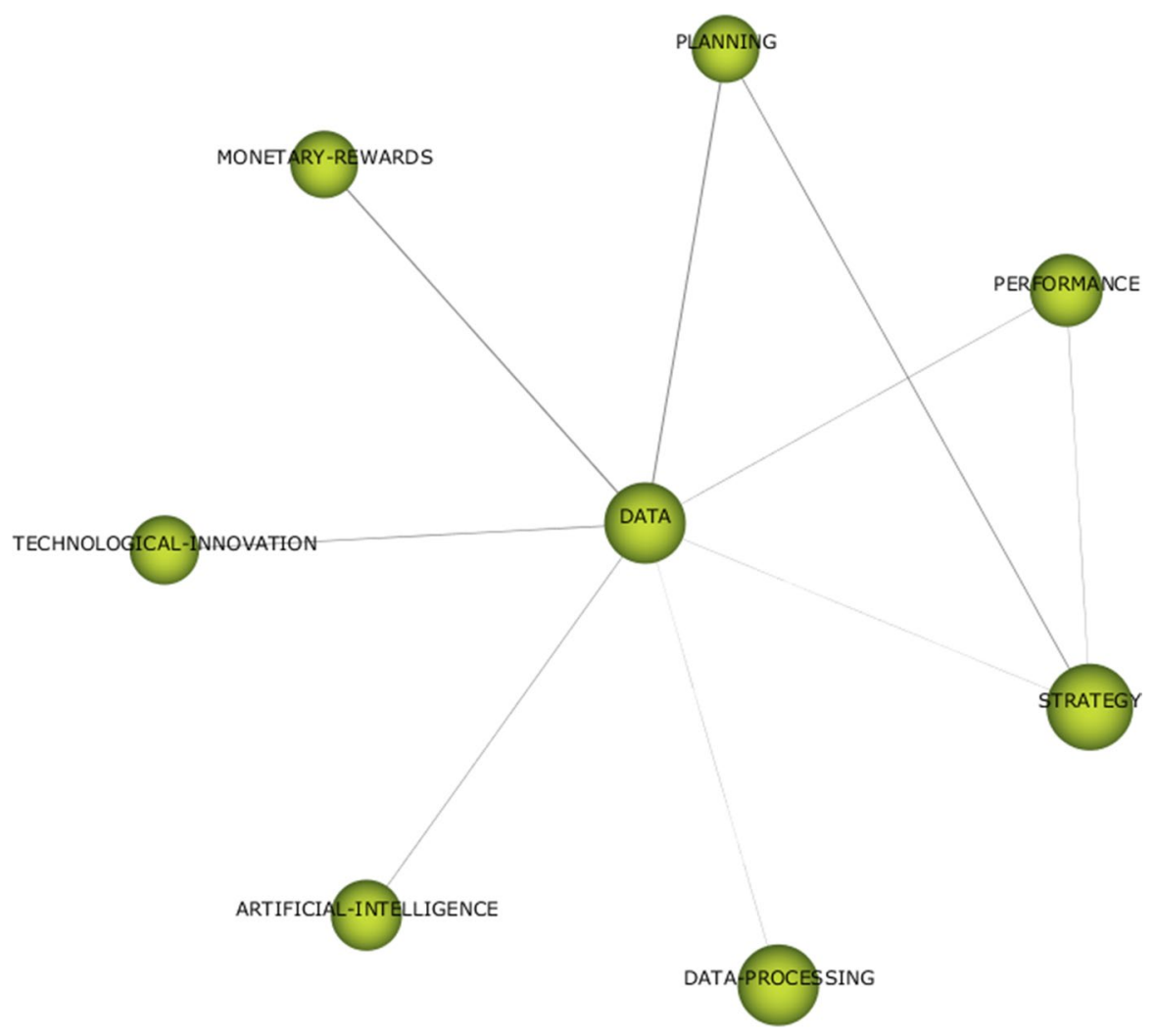

Fig. 14 Cluster's network Data- Source SciMAT- Own Elaboration

working relationship between organizations and the Online communities of solution providers to increase the value of their online competitions (Fig. 13).

\subsection{Cluster 8: data}

Analyzing this cluster centered on Data (Fig. 14), we find that crowdsourcing is emerging as a novel framework to find robust methodologies (Saez-Rodriguez et al. 2016) in those scientific disciplines where the analysis and Processing of complex and massive Data is a fundamental issue. In the crowdsourcing approach, interpreted as an outside-in OI mechanism, it is crucial to have a clear Planning and Strategy to improve the Performance of innovation in its many forms, such as Technological innovation, products/service innovation, process/production innovation, operational/management/organizational innovation, business model innovation. About this, Bagherzadeh et al. (2019) examined the influence of outside-in OI on innovation performance considering the mediating roles of knowledge sharing and innovation strategy finding that "knowledge sharing and innovation strategy fully mediate the relationship between outside-in OI and innovation performance". It is 


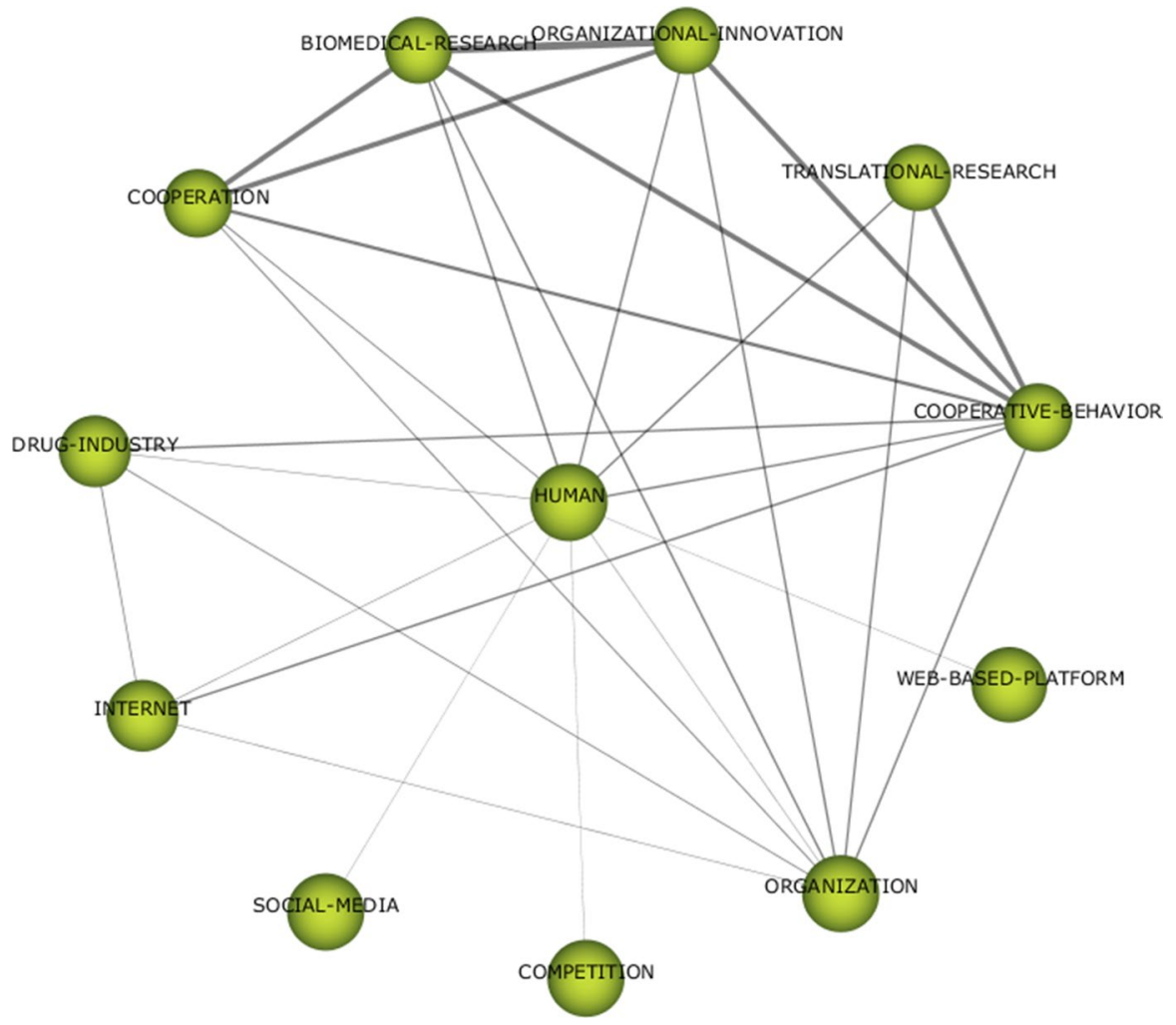

Fig. 15 Cluster's network Human - Source SciMAT- Own Elaboration

interesting to notice here that, as Battistella and Nonino (2013) stated, more than on Monetary rewards, the OI Platforms depend on different motivations to attract different innovation roles (Fig. 15).

We also observe that some research streams (e.g. Buecheler et al. 2010) deal with the applicability of agent design principles from Artificial Intelligence research to crowdsourcing.

\subsection{Cluster 9: human}

In terms of Organization and social interactions, compared to other computersupported cooperative work, such as social computing, social machines, in the crowdsourcing process, the emphasis is on Human participants (Niu et al. 2018). Kazai et al. (2013) addressed the "human factor" issue, exploring the human characteristics of the crowd that shape the experience of contributors with the crowdsourced task. Moreover, as observed by Buettner (2015), since all markets including human factors run under uncertainty, crowdsourcing needs to implement well-calibrated coordination mechanisms to manage the human resources 
involved. Adopting OI strategies requires Organizational innovation, that needs to be linked to a new and more entrepreneurial culture, open and Cooperative behavior, and a collaborative mindset of the people (Fig. 15).

Over the last years, thanks to the advent of the Internet and tools such as Social media and Web-based platforms, natural and applied sciences, like biology, medicine, pharmaceutics, have also become more decentralized, bottomup, and scalable than ever before. New models for OI, such as open sourcing, crowdsourcing, public-private partnerships, innovations centers, Bilateral Academic Collaborations, and the virtualization of R\&D have carved out a significant space for organizations in Biomedical research, Translational research, and Drug industry (Carter et al. 2017; Schuhmacher et al. 2018). Generalizing what was stated by Lessl and Asadullah (2014) in the case of drug discovery, crowdsourcing and OI approaches foster Cooperation and harness the complementary expertise and knowledge of academic and industrial partners. Saez-Rodriguez et al. (2016) highlighted that "collaborative scientific Competitions, known as challenges, encourage OI, create collaborative communities, to solve diverse and important biomedical problems".

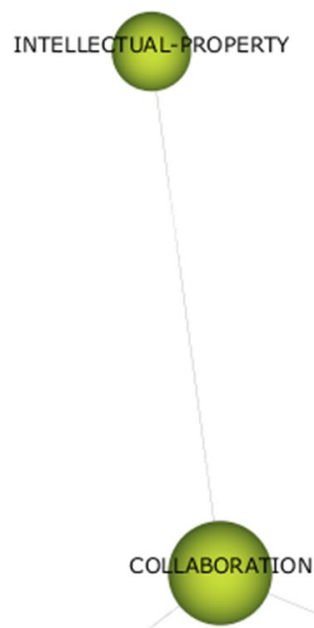

SMALL-AND-MEDIUM-ENTERPRISE

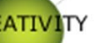

Fig. 16 Cluster's network Collaboration-Source SciMAT- Own Elaboration 


\subsection{Cluster 10: collaboration}

Even if this is the smallest cluster consisting of four elements (Fig. 16), with Creativity, Small and Medium Enterprise, and Intellectual Property in addition to the central node Collaboration, it offers the chance to discuss interesting aspects, recently addressed in the literature.

In collaborative and open environments, including crowdsourcing and open and collaborative innovation, IPR management and protection constitute key issues. Fantoni et al. (2016) illustrated a novel architecture for collaborative crowdsourcing where thanks to an IT platform and an IPR tracking system, the involvement of firms is facilitated and users' participation is promoted, exploiting simultaneously collaboration and meritocracy. As for Small and Medium enterprises, OI entails opportunities and challenges for SMEs (Rahman 2016) and through various innovation practices, can lead to success cases (Cardoso and Ramos 2013), enabling knowledge creation and collaboration amongst different players in a network. The real benefit of both OI and crowdsourcing approaches can only be achieved when the power and creativity of crowds can be fully harnessed by converting innovative ideas into practice with actionable plans and tools (Carter et al. 2017).

\section{Discussions}

In the previous section, we illustrated the output of the co-word analysis, describing the thematic networks and their conceptual meaning. Looking at the clusters obtained and considering them two by two, we recognized that they are the expression of different but complementary aspects: behavioral aspect (Human and Collaboration), technological aspect (Web and Platforms), managerial aspect (Information Management and Data), and strategic aspect (Innovation and Product Development). In our opinion, these four specific dimensions, some of them already investigated in the literature (e.g. Chiu et al. 2014), represent the perspectives to be adopted for a better understanding of crowdsourcing in the intellectual structure of OI. Recalling that our research aims to shed light on the relationship between OI and crowdsourcing, at the end of this section, we propose an integrated view to interpret and synthesize the results.

\subsection{Strategic dimension}

The strategic dimension represents the strategic objectives to pursue. We recognized in the strategic dimension the desired outcome, the valuable results that an organization aims at when it decides to implement crowdsourcing initiatives in the context of an OI approach. In our analysis, the topics included in the thematic networks Innovation and Product Development represent this dimension, since they are both strategical objectives to achieve. Innovation is recognized as a source of sustainable competitive advantage and to that end, the use of the crowd as an innovation partner represents a big opportunity (Boudreau and Lakhani 2013). Through the crowdsourcing model, the company can obtain support for problem-solving, idea generation, design, and 
development, testing, and commercialization. As Di Benedetto (2014) observed, OI implies a strategic commitment by the company to integrate its internal knowledge with the external one to improve its innovation performance. For this reason, there is a need for alignment between the implementation of crowdsourcing initiatives for innovation and product development, and the strategic vision at the corporate level. Moreover, it is important to align the interest of the different stakeholders involved. The need for this unity of purposes is also emphasized by Kohler (2015), who highlights the importance of involving the crowd in the platform's strategic issues.

\subsection{Managerial dimension}

The managerial dimension concerns the organizational and process level, and it involves all the managerial issues that an organization has to deal with, on both levels. This dimension regards all the aspects related to knowledge and information management, design, development, and implementation of an appropriate business model, management of ambidexterity, and tensions between the different actors. It also covers the managerial capabilities and competencies required, that are essential to proceed along the established strategic direction. The themes inside the cluster Information Management and Data represent the managerial dimension. Examples of this are how to manage information and knowledge, how to collect and process data, how to design tasks, how to manage a crowd, and how to govern the entire process. From an organizational point of view, crowdsourcing also provides an innovative way to get work done and entails a more flexible and dynamic operations flow (Wilson et al. 2018). For it to work, every actor involved-organizations' members, participants, intermediaries - must be prepared and engaged. This organizational change means that also employees should be properly managed, prepared, and educated for the introduction of this new approach (Lüttgens et al. 2014). Starting with the negative example of Quirky, Kohler (2015) proposes a series of useful lessons for managers to build an effective and sustainable business model and guide their actions in crowd management and platform design, including maintaining effective value creation, sharing value captured, building crowd culture, aligning the aims of the company and the crowd.

\subsection{Behavioral dimension}

This dimension refers to the behaviors of the stakeholders involved (individuals, seekers, firms, intermediaries) and how they interact. The interest here is in what the motivational drivers are, what attitudes the different actors maintain, what kind of interaction they have. In our opinion, the behavioral aspect is represented by the themes related to the Human and Collaboration clusters, as they concern the individuals, their motivations and attitudes, how they act and interact. As discussed in the literature, a distinctive feature of crowdsourcing is the emphasis on the human component. The human "essence" of the crowd has a big impact on the dynamics of crowdsourcing: for example, concerning the tension between two conflicting drivers, collaboration and competition, as noted by various experts in the field, or the 
motivations of contributors that may influence the performance of the required tasks. Many studies (Brabham 2010; Boudreau et al. 2011; Frey et al. 2011; Battistella and Nonino 2013; Acar 2019) have provided a better understanding of the intrinsic and extrinsic motivations, incentives, and reward modes best suited to attract users to participate and contribute to the innovation process. At this level, another key element is trust. The development of mutual trust between seekers, solvers, and the intermediary is essential in the OI perspective to ensure success.

\subsection{Technological dimension}

The technological dimension is related to the information systems, the digital technologies used for supporting the process, and the emerging technologies in the field. The thematic networks Platforms and Web represent the technological aspect. Technology plays a key role by acting as an enabler since it is considered essential in overcoming communication boundaries and favoring knowledge flows (Santoro et al. 2018) and it can be used as a facilitator (Geiger and Schader 2014). The emergence of the Web has acted as a catalyst for the affirmation and success of crowdsourcing since it has put companies and organizations in a position to harness the power of the crowd with little effort (Ghezzi et al. 2018) and almost no limits, thanks to its ubiquity, diffusion, and aggregation capacity (de Mattos et al. 2018). In particular, the platforms have become the essential tools that can be used to exploit collective intelligence to gain and develop new ideas for products and services and to generate new knowledge. Therefore, Platforms and the Web are enabling technologies that allow the successful implementation of the crowdsourcing process in the OI paradigm. As discussed in the literature (e.g., de Mattos et al. 2018), the three concepts of OI, crowdsourcing, and technology are interconnected to create a fertile and innovation-friendly virtual environment. In this sense, the platforms represent an effective and enabling tool to implement OI strategies, to realize product and service innovation, and to manage several issues regarding information use, IPR management, transaction costs, and competence requirements.

\subsection{An integrated view}

The escalation of the economic crisis, the intensification of global competition, the reduction of the life cycle of new products, and the difficulty of sustaining the increasing expenses in research and development (R\&D) are just some of the causes of the change that occurred in the innovative processes of companies and their R\&D departments. Therefore, to respond to the new challenges proposed by the market and to foster technological development and the implementation of radical but also incremental innovation, organizations, and firms have begun to develop dynamics of OI affiliated by a growing propensity to carry out collaborations for innovation with external partners, valuable sources of knowledge and expertise, and the implementation of specific innovative initiatives. To achieve this objective, it is crucial to have a clear baseline strategy and implement appropriate managerial actions. Thanks to the 


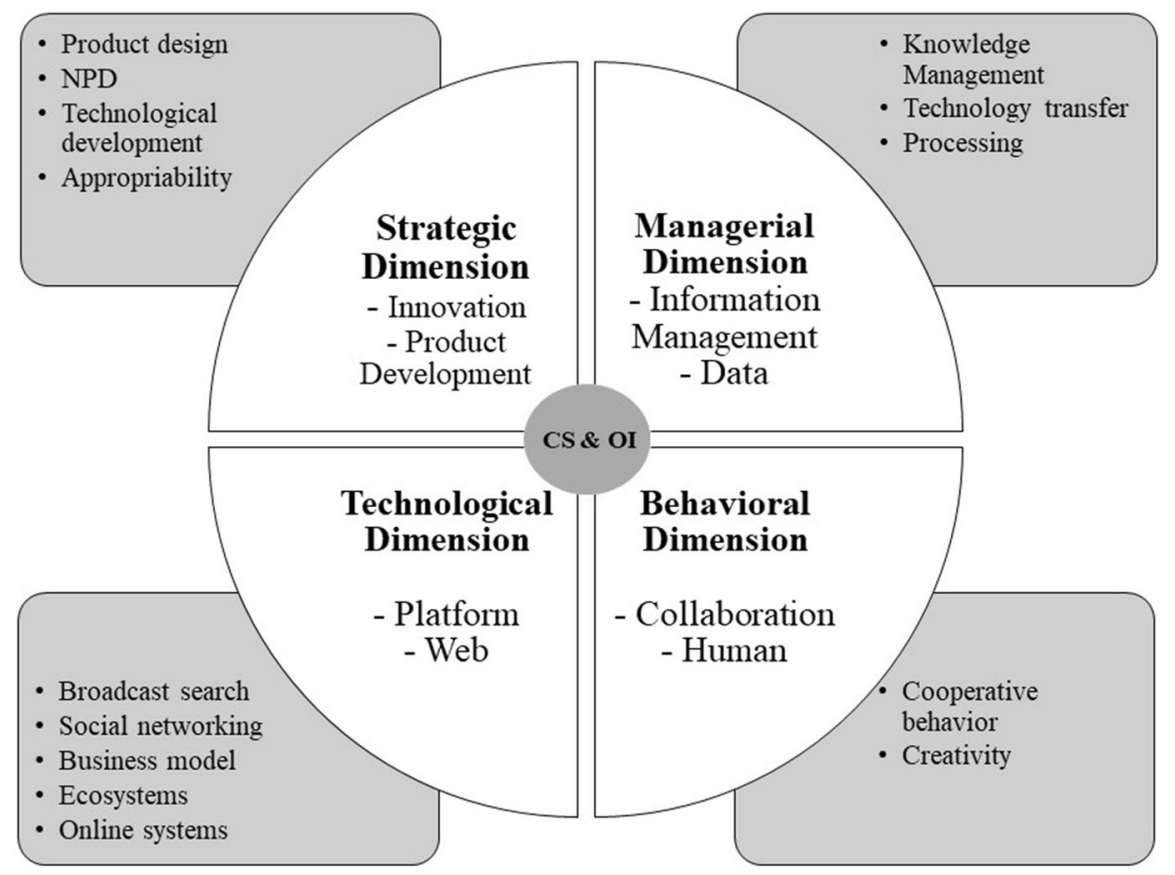

Fig. 17 The dimensions that characterize the intersection between OI and crowdsourcing

previous analysis, we have identified four dimensions, as illustrates in Fig. 17. In the following, we propose an interpretation of how they can form a coherent framework that characterizes the intersection between the two topics of OI and crowdsourcing.

In the context of OI, the crowdsourcing approach allows to promote cooperation and harness the complementary expertise and knowledge of seekers and solvers (Frey et al. 2011). The adoption of OI strategies entails a reorganization of how processes are carried out, that need to be linked to a new and more entrepreneurial culture, an open and cooperative behavior, and a collaborative mindset of the people involved. Moreover, the implementation of practices that allow seekers to draw on the solvers' intrinsic and extrinsic motivation to increase their participation is essential (Acar 2019). Similarly, the adoption of crowdsourcing requires implementing well-calibrated coordination mechanisms to manage the human resources involved (Buettner 2015; Moellers et al. 2018). In fact, in terms of organization and social interactions, compared to other computer-supported cooperative works, in the crowdsourcing approach, the emphasis is on human participants. Therefore, the managerial and the behavioral dimensions must go hand in hand. Moreover, as remarked by Majchrzak and Malhotra (2013) the management of the two conflicting drives, competition, and collaboration, passes through the creation of an appropriate architecture that encourages and stimulates both. This has repercussions is on the managerial aspect, is on the technological aspect, that, in this context, beyond being an enabler it is also a "shaper" able to optimize OI in general and the crowdsourcing process in particular (Majchrzak and Malhotra 2013). Therefore, as Devece 
et al. (2019) stated, technology plays a prominent role, but technological capabilities should be integrated by organizational and managerial competencies. For that more, a clear strategy and vision should inspire and mold the technological initiatives, and in turn, managerial skills represent a key element in strategy implementation (Devece et al. 2019). From a business strategy perspective, one of the challenges is how to enable interactions and orchestrate firm's and crowd's activities (Kohler 2015). In this regard, innovation intermediaries can facilitate the whole innovation process, enabling innovation exchanges between organizations and crowds, covering knowledge search, problem-solving, and connecting and coordinating knowledge and technology transfer between actors (Feller et al. 2012; Colombo et al. 2013; De Silva et al. 2018). Finally, the fourth component of the diagram in Fig. 17 represents the two strategic objectives, product development and innovation. Crowdsourcing for new product development has become very popular among firms in different industries; it is not only a source for idea generation, since it could be fruitfully used in each subsequent stage too, from screening and evaluation up to commercialization. The adoption of the OI paradigm can help the reduction of $\mathrm{R} \& \mathrm{D}$ costs, the sharing of the risks of innovation, and, in some cases reducing the time to market of new products and services. The second objective is innovation in its many forms (technological/operational/organizational innovation, business model innovation, etc.). The real benefit of both OI and crowdsourcing approaches can only be achieved when the creativity and knowledge generated by the external partner (e.g., crowd) are funneled and the value generated is absorbed through dedicated processes and tools, since OI is not possible without absorptive capacity as an internal capability of innovating companies. In the OI context, to successfully implement a crowdsourcing initiative, it is necessary to take into account the four dimensions identified (strategic, managerial, behavioral, technological) that must integrate and advance at the same pace.

\subsection{Proposals for future research}

The analysis of clusters and the identification of four characteristic dimensions allowed us to identify several emerging and promising questions to address future research. We summarized and sorted them in the table below, according to the four dimensions. The questions proposed in Table 3 aim, on the one hand, to systematize the main issues still open in the existing literature and, on the other, to propose novel ideas to inspire the future work of scholars and researchers. To provide a deeper comprehension of the issues debated in the paper, at the strategic level some of the main concerns regard the value creation and value capture, and how to measure the performance of the crowdsourcing process. We believe that future research should primarily identify metrics to quantify and monitor the impact of crowdsourcing on the innovation process, including whether or not there are differences by the industrial sector or type of company. As for the managerial dimension, future research should examine in more detail what factors determine the seeker's choice of a certain type of architecture and how the 


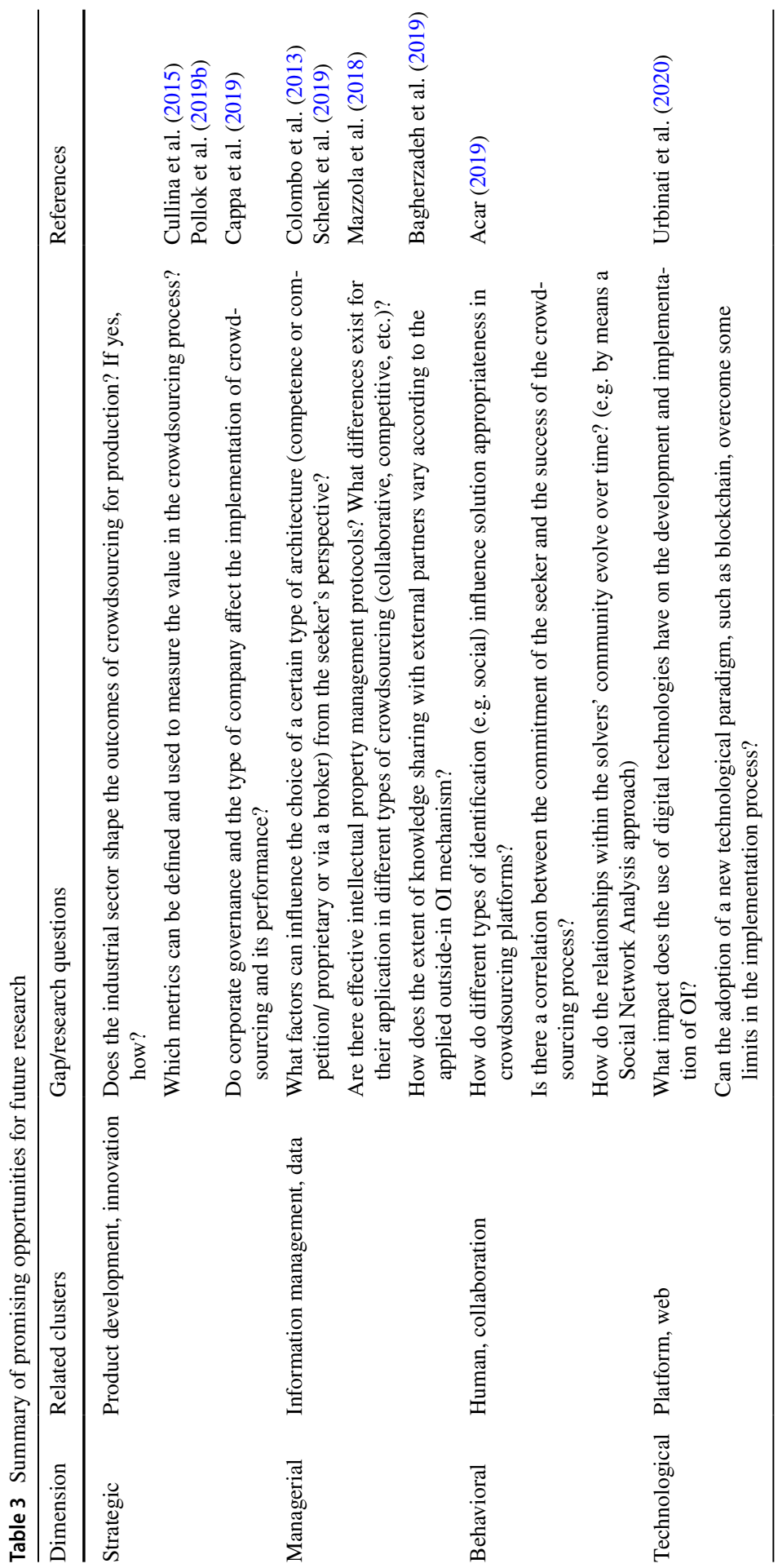


knowledge sharing and transfer towards external partners changes according to the type of inbound OI mechanism used. Moreover, there are questions still open regarding the management of intellectual property. As for the behavioral dimension, we mainly encourage a Social Network Analysis approach to better understand how the relationships within the solvers' community evolve and to detect any differences in the way of relating in different types of crowdsourcing (competitive, collaborative, internal, external, via a broker, etc.). Future studies could also address the correlation between the successful performance of the crowdsourcing process, the commitment of the seeker, and the solvers' motivation. Nowadays, new opportunities for firms and organizations to manage the innovation process in an open and collaborative way are favored by the development of digital technologies. Despite many pieces of evidence in this sense, the role of digital technologies in the context of OI deserves further investigation. In particular, the emergence of new technological paradigms, like blockchain and Big Social Data, opens new interesting opportunities for the development of OI and crowdsourcing. In our opinion, these questions should be addressed with priority to timely respond to current issues with relevant implications for both practitioners and academics.

\section{Conclusions}

This article constitutes the first attempt to carry out a comprehensive and systematic review of the literature on crowdsourcing and OI applying bibliometric techniques. It is based on the literature on both these topics published between 2008 and 2019 on the Scopus database from Elsevier. The aim is to respond to recent calls for a better understanding of the concept of crowdsourcing in relation to other similar and associated concepts (Estellés-Arolas and González-Ladrón-de-Guevara 2012). Despite the updated and rich dataset of documents analyzed and the systematic and rigorous approach used, this paper is not without limitations. First of all, the co-word analysis presented in the second part of the study was conducted on the keywords indicated by the authors of the papers, therefore there may be some distortions due to the choices made by the authors themselves; secondly, a different sensitivity in the calibration of the tool SciMAT could affect the outcomes. Taking all this into account, it is possible to draw conclusions and set out potential lines for future research. Also, we can derive the following implications for academia. By analyzing the literature, we identified the structure and the theoretical core elements from which research themes and problems were inherited and adapted in the context of OI and crowdsourcing. As for the content, through the co-word analysis, we identified ten thematic clusters, as deeply described above. This way, we provided a rich and timely discussion on the topics under examination, helping to provide a better understanding of crowdsourcing in the intellectual structure of OI. Looking at the themes that emerged from the co-word analysis, we noticed that the arguments taken two by two shed light on different aspects. Therefore, we organized the thematic networks into a framework (as shown in Fig. 17) along four dimensions 
(strategic, managerial, behavioral, technological), and then we proposed an integrated interpretation.

Regarding the implications for practitioners, these dimensions constitute the four pillars that an organization must analyze and correctly combine to benefit from the adoption of the crowdsourcing approach from an OI perspective. A clear strategy should inspire and form technology initiatives. Technology plays a major role, being a shaper as well as an enabler, but technological capabilities should be complemented by organizational and managerial skills. In turn, the managerial dimension, a key element in strategy implementation, must go hand in hand with the behavioral dimension, as the human factor is essential in this context.

Finally, for each dimension, we discussed specific research opportunities and indicated some bibliographical references. We summarized this range of issues that can be further explored in future studies in Table 3. We believe that OI and crowdsourcing are still appealing and promising for new research horizons and for their implementation at the corporate level.

\section{Appendix A: Fig. 3 legend}

\begin{tabular}{ll}
\hline Labels & Corresponding documents \\
\hline $\begin{array}{l}\text { Surowiecki (2005) } \\
\text { Chesbrough (2003a, b) }\end{array}$ & $\begin{array}{l}\text { Surowiecki J (2005) The Wisdom of Crowds. Anchor Books, New York } \\
\text { Chesbrough HW (2003) The era of open innovation. MIT Sloan Manag Rev } \\
\text { Howe (2008) }\end{array}$ \\
$\begin{array}{l}\text { Howe J (2008) Crowdsourcing: Why the Power of the Crowd Is Driving the } \\
\text { Rapoport (1970) }\end{array}$ & $\begin{array}{l}\text { Rapoport RN (1970) Three dilemmas in action research. Human Relations, 23, } \\
\text { Chesbrough HW (2006) Open business models: How to thrive in the new inno- } \\
\text { vation landscape. Harvard Business School Press, Boston, MA }\end{array}$ \\
Melin (2000) & $\begin{array}{c}\text { Melin G (2000) Pragmatism and self-organization Research collaboration on } \\
\text { the individual level. Res Policy 29: 31-40 }\end{array}$ \\
\hline
\end{tabular}

\section{Appendix B: Fig. 4 legend}

\begin{tabular}{lc}
\hline Labels & Corresponding documents \\
\hline Hertel et al. (2003) & $\begin{array}{c}\text { Hertel G, Niedner S, Herrmann S (2003) Motivation of software devel- } \\
\text { opers in open source projects: An Internet-based survey of contributors } \\
\text { to the Linux kernel. Res Policy 32:1159-1177 }\end{array}$ \\
West and O'Mahony (2008) & $\begin{array}{c}\text { West J, O'mahony S (2008) The role of participation architecture in } \\
\text { growing sponsored open source communities. Ind Innov 15:145-168 }\end{array}$ \\
\hline
\end{tabular}


Labels

Sawhney et al. (2005)

Brabham (2010)

Von Hippel E (2005)

Brabham (2008)

Boudreau et al. (2011)

Tapscott and Williams (2006)

Kozinets (2010)

Bonabeau (2009)

Feller et al. (2012)
Corresponding documents

Sawhney M, Verona G, Prandelli E (2005) Collaborating to create: The internet as a platform for customer engagement in product innovation. $\mathrm{J}$ Interact Mark 19:4-17

Brabham DC (2010) Moving the crowd at threadless: Motivations for participation in a crowdsourcing application. Inf Commun Soc 13:1122-1145

Von Hippel E (2005) Democratizing Innovation. MIT Press, Cambridge, MA

Brabham DC (2008) Crowdsourcing as a model for problem solving: An introduction and cases. Convergence 14:75-90

Boudreau KJ, Lacetera N, Lakhani KR (2011) Incentives and problem uncertainty in innovation contests: An empirical analysis. Manage Sci 57:843-863

Tapscott D, Williams AD (2006) Wikinomics: How Mass Collaboration Changes Everything., New York: Penguin

Kozinets RV (2010) Netnography. Doing Ethnographic Research Online, Thousand Oaks. CA: Sage Publications

Bonabeau E (2009) Decisions 2.0: the power of collective intelligence. MIT Sloan Manag Rev, 50, 45-52

Feller J, Finnegan P, Hayes J, O'Reilly P (2012) “Orchestrating” sustainable crowdsourcing: A characterisation of solver brokerages. J Strateg Inf Syst 21:216-232

\section{Appendix C: Fig. 5 legend}

Label

O’Mahony and Ferraro (2007)

Sieg et al. (2010)

Hertel et al. (2003)

Estelles-Arolas and GonzalezLadron-De-Guevara (2012)

Piezunka and Dahlander (2015)

Cohen and Levinthal (1990)

Von Hippel (2005)
Corresponding document

O'Mahony S, Ferraro F (2007) The emergence of governance in an open source community. Acad Manag J 50:1079-1106

Sieg JH, Wallin MW, Von Krogh G (2010) Managerial challenges in open innovation: a study of innovation intermediation in the chemical industry. R D Manag 40: 281-291

Hertel G, Niedner S, Herrmann S (2003) Motivation of software developers in open source projects: An Internet-based survey of contributors to the Linux kernel. Res Policy 32:1159-1177

Estellés-Arolas E, González-Ladrón-de-Guevara F (2012) Towards an integrated crowdsourcing definition. J Inf Sci 38:189-200

Piezunka H, Dahlander L (2015) Distant Search, Narrow Attention: How Crowding Alters Organizations' Filtering of Suggestions in Crowdsourcing. Acad Manag J 58:856-880

Cohen WM, Levinthal DA (1990) Absorptive Capacity: A New Perspective on Learning and Innovation. Administrative Sci Quarterly, 35:128-152

Von Hippel E (2005) Democratizing Innovation, MIT Press, Cambridge, MA 


Label Corresponding document

Terwiesch and $\mathrm{Xu}(2008)$

Terwiesch C, Xu Y (2008) Innovation contests, open innovation, and multiagent problem solving. Manage Sci 54:1529-1543

Howe (2008)

Howe J (2008) Crowdsourcing: Why the Power of the Crowd Is Driving the Future of Business, Crown Publishing Group, New York

Surowiecki (2005)

Surowiecki J (2005) The Wisdom of Crowds. Anchor Books, New York

Galateanu and Avasilcai (2017)

Saxton et al. (2013)

Galateanu E, Avasilcai S (2017) Emerging Creative Ecosystems: Platform Development Process. Ann ORADEA Univ Fascicle Manag Technol Eng Volume XXV:

Saxton GD, Oh O, Kishore R (2013) Rules of Crowdsourcing: Models, Issues, and Systems of Control. Inf Syst Manag 30:2-20

Von Hippel and Von Krogh (2003) Von Hippel E, Von Krogh G (2003) Open source software and the "private-collective" innovation model: Issues for organization science. Organ Sci 14:209-223+225

Wernerfelt (1984)

Wernerfelt B (1984) A resource-based view of the firm. Strateg Manag J, 5, 171-180

Chesbrough and Rosenbloom (2002) Chesbrough H, Rosenbloom RS (2002) The role of the business model in capturing value from innovation: evidence from Xerox Corporation's technology spin-off companies. Ind Corp Chang 11:529-555

Lilien et al. (2002)

Lilien GL, Morrison PD, Searls K, et al. (2002) Performance assessment of the lead user idea-generation process for new product development. Manage Sci 48:1042-1059

Poole and Van de Ven (1989)

Poole MS, van de AH (1989) Using Paradox to Build Management and Organization Theories. Acad Manag Rev

Authors' contributions All authors contributed to the study conception and design. Material preparation, data collection, and analysis were performed by SV, MG and LC. The first draft of the manuscript was written by SV and all authors commented on previous versions of the manuscript. All authors read and approved the final manuscript.

Funding Open access funding provided by Università degli Studi di Roma Tor Vergata within the CRUICARE Agreement. No funds, grants, or other support was received.

Availability of data and material The data that support the findings of this study are available from the corresponding author, upon reasonable request.

\section{Declarations}

Conflict of interest The authors have no conflicts of interest to declare that are relevant to the content of this article.

Open Access This article is licensed under a Creative Commons Attribution 4.0 International License, which permits use, sharing, adaptation, distribution and reproduction in any medium or format, as long as you give appropriate credit to the original author(s) and the source, provide a link to the Creative Commons licence, and indicate if changes were made. The images or other third party material in this article are included in the article's Creative Commons licence, unless indicated otherwise in a credit line to the 
material. If material is not included in the article's Creative Commons licence and your intended use is not permitted by statutory regulation or exceeds the permitted use, you will need to obtain permission directly from the copyright holder. To view a copy of this licence, visit http://creativecommons.org/licen ses/by/4.0/.

\section{References}

Acar OA (2019) Motivations and solution appropriateness in crowdsourcing challenges for innovation. Res Policy 48:103716. https://doi.org/10.1016/j.respol.2018.11.010

Afuah A (2014) Business model innovation concepts, analysis, and cases. Taylor and Francis Group, New York

Afuah A, Tucci CL (2013) Value capture and crowdsourcing. Acad Manag Rev 38:457-460. https://doi. org/10.5465/amr.2012.0423

Albors J, Ramos JC, Hervas JL (2008) New learning network paradigms: Communities of objectives, crowdsourcing, wikis and open source. Int J Inf Manage 28:194-202. https://doi.org/10.1016/j.ijinf omgt.2007.09.006

Alcaide-Muñoz L, Rodríguez-Bolívar MP, Cobo MJ, Herrera-Viedma E (2017) Analysing the scientific evolution of e-Government using a science mapping approach. Gov Inf Q 34:545-555. https://doi. org/10.1016/j.giq.2017.05.002

Alexy O, Criscuolo P, Salter A (2012) Managing Unsolicited Ideas for R\&D. Calif Manage Rev 54:116139. https://doi.org/10.1525/cmr.2012.54.3.116

Ali-Hassan H, Allam H (2016) Comparing crowdsourcing initiatives: Toward a typology development. Can J Adm Sci 33:318-331. https://doi.org/10.1002/cjas.1395

Avasilcai S, Bujor A (2018) Open innovation in creative industries. Part II: the case of threadless. IOP Conf Ser Mater Sci Eng. https://doi.org/10.1088/1757-899X/400/6/062002

Bagherzadeh M, Markovic S, Cheng J, Vanhaverbeke W (2019) How does outside-in open innovation influence innovation performance? Analyzing the mediating roles of knowledge sharing and innovation strategy. IEEE Trans Eng Manag. https://doi.org/10.1109/TEM.2018.2889538

Barchi M, Greco M (2018) Negotiation in open innovation: a literature review. Gr Decis Negot 27:343374. https://doi.org/10.1007/s10726-018-9568-8

Battistella C, Nonino F (2013) Exploring the impact of motivations on the attraction of innovation roles in open innovation web-based platforms. Prod Plan Control 24:226-245. https://doi.org/10.1080/ 09537287.2011.647876

Bogers M, West J (2012) Managing distributed innovation: strategic utilization of open and user innovation. Creat Innov Manag 21:61-75. https://doi.org/10.1111/j.1467-8691.2011.00622.x

Bogers M, Zobel AK, Afuah A et al (2017) The open innovation research landscape: established perspectives and emerging themes across different levels of analysis. Ind Innov 24:8-40. https://doi.org/10. $1080 / 13662716.2016 .1240068$

Boudreau K, Lakhani K (2009) How to manage outside innovation: competitive markets or collaborative communities? Sloan Manage Rev 50:69-76

Boudreau KJ, Lakhani KR (2013) Using the crowd as an innovation partner. Harv Bus Rev 91(4):60-69, 140

Boudreau KJ, Lacetera N, Lakhani KR (2011) Incentives and problem uncertainty in innovation contests: An empirical analysis. Manage Sci 57:843-863. https://doi.org/10.1287/mnsc.1110.1322

Brabham DC (2008) Crowdsourcing as a model for problem solving: an introduction and cases. Convergence 14:75-90. https://doi.org/10.1177/1354856507084420

Brabham DC (2009) Crowdsourcing the public participation process for planning projects. Plan Theory 8:242-262. https://doi.org/10.1177/1473095209104824

Brabham DC (2010) Moving the crowd at threadless: motivations for participation in a crowdsourcing application. Inf Commun Soc 13:1122-1145. https://doi.org/10.1080/13691181003624090

Brabham DC (2013) Crowdsourcing. MIT Press

Buecheler T, Sieg JH, Füchslin RM, Pfeifer R (2010) Crowdsourcing, open innovation and collective intelligence in the scientific method: A research agenda and operational framework. In: Artificial 
Life XII Proc of the 12th Int Conf Synth Simul Living Syst ALIFE 2010, pp 679-686. https://doi. org/10.21256/zhaw-4094

Buettner R (2015) A systematic literature review of crowdsourcing research from a human resource management perspective. Proc Annu Hawaii Int Conf Syst Sci. https://doi.org/10.1109/HICSS.2015. 549

Callon M, Courtial J-P, Turner WA, Bauin S (1983) From translations to problematic networks: An introduction to co-word analysis. Soc Sci Inf 22:191-235

Callon M, Courtial JP, Laville F (1991) Co-word analysis as a tool for describing the network of interactions between basic and technological research: The case of polymer chemsitry. Scientometrics 22:155-205. https://doi.org/10.1007/BF02019280

Cappa F, Oriani R, Pinelli M, De Massis A (2019) When does crowdsourcing benefit firm stock market performance?. Res Policy 48(9):103825. https://doi.org/10.1016/j.respol.2019.103825

Cardoso M, Ramos I (2013) Rvolta, a case for open innovation: How can a SME be innovative in a competitive industrial environment? In: Small and medium enterprises: concepts, methodologies, tools, and applications. IGI Global, Hershey, PA, pp 1562-1579

Carter AJ, Donner A, Lee WH, Bountra C (2017) Establishing a reliable framework for harnessing the creative power of the scientific crowd. PLoS Biol 15:1-9. https://doi.org/10.1371/journal.pbio. 2001387

Chesbrough HW (2003) Open Innovation: The new imperative for creating and profiting from technology. Harvard Business School Publishing Corporation, Boston

Chesbrough HW (2003) The era of open innovation. MIT Sloan Manag Rev 44(3):35-41

Chesbrough H, Rosenbloom RS (2002) The role of the business model in capturing value from innovation: evidence from Xerox Corporation's technology spin-off companies. Ind Corp Chang 11:529_ 555. https://doi.org/10.1093/icc/11.3.529

Chesbrough H, Brunswicker S (2014) A fad or a phenomenon?: The adoption of open innovation practices in large firms. Res-Technol Manag 57(2):16-25

Chiu CM, Liang TP, Turban E (2014) What can crowdsourcing do for decision support? Decis Support Syst 65:40-49. https://doi.org/10.1016/j.dss.2014.05.010

Cobo MJ, López-Herrera AG, Herrera-Viedma E, Herrera F (2011) An approach for detecting, quantifying, and visualizing the evolution of a research field: a practical application to the Fuzzy Sets Theory field. J Informetr 5:146-166. https://doi.org/10.1016/j.joi.2010.10.002

Cobo MJ, López-Herrera AG, Herrera-Viedma E, Herrera F (2012) SciMAT: a new science mapping analysis software tool. J Am Soc Inf Sci Technol 63:1609-1630. https://doi.org/10.1002/asi

Cobo MJ, Chiclana F, Collop A et al (2014) A bibliometric analysis of the intelligent transportation systems research based on science mapping. IEEE Trans Intell Transp Syst 15:901-908. https://doi. org/10.1109/TITS.2013.2284756

Cobo MJ, Wang W, Laengle S et al (2018) Co-words analysis of the last ten years of the international journal of uncertainty, fuzziness and knowledge-based systems. Inf Process Manag Uncertain Knowledge-Based Syst Appl. https://doi.org/10.1007/978-3-319-91479-4

Cohen WM, Levinthal DA (1990) Absorptive capacity: a new perspective on learning and innovation. Adm Sci Q 35:128-152. https://doi.org/10.2307/2393553

Colombo G, Buganza T, Klanner IM, Roiser S (2013) Crowdsourcing intermediaries and problem typologies: An explorative study. Int J Innov Manag. https://doi.org/10.1142/S1363919613500059

Cullina E, Conboy K, Morgan L (2015) Measuring the crowd: a preliminary taxonomy of crowdsourcing metrics. In: Proceedings of the 11th international symposium on open collaboration, pp 1-10

Dahlander L, Gann DM (2010) How open is innovation? Res Policy 39:699-709. https://doi.org/10. 1016/j.respol.2010.01.013

de Mattos CA, Kissimoto KO, Laurindo FJB (2018) The role of information technology for building virtual environments to integrate crowdsourcing mechanisms into the open innovation process. Technol Forecast Soc Change 129:143-153. https://doi.org/10.1016/j.techfore.2017.12.020

De Silva M, Howells J, Meyer M (2018) Innovation intermediaries and collaboration: Knowledge-based practices and internal value creation. Res Policy 47:70-87. https://doi.org/10.1016/j.respol.2017. 09.011

Devece C, Palacios-Marqués D, Ribeiro-Soriano DE (2019) IT-based strategy, capabilities, and practices: crowdsourcing implementation in market-oriented firms. Rev Manag Sci. https://doi.org/10.1007/ s11846-019-00369-w

Di Benedetto CA (2014) Open innovation and the value of crowds: Implications for the fashion industry. J Glob Fash Mark 5:26-38. https://doi.org/10.1080/20932685.2013.859876 
Dimitrova S, Scarso E (2017) The impact of crowdsourcing on the evolution of knowledge management: Insights from a case study. Knowl Process Manag 24:287-295. https://doi.org/10.1002/kpm.1552

Ebner W, Leimeister JM, Krcmar H (2009) Community engineering for innovations: the ideas competition as a method to nurture a virtual community for innovations. R\&D Manag 39(4) 342-356. https://doi.org/10.1111/j.1467-9310.2009.00564.x

Estellés-Arolas E, González-Ladrón-de-Guevara F (2012) Towards an integrated crowdsourcing definition. J Inf Sci 38:189-200. https://doi.org/10.1177/016555150000000

Fantoni G, Apreda R, Valleri P et al (2016) IPR tracking system in collaborative environments. IEEE Int Technol Manag Conf ICE 2009. https://doi.org/10.1109/ITMC.2009.7461427

Feller J, Finnegan P, Hayes J, O'Reilly P (2012) “Orchestrating” sustainable crowdsourcing: A characterisation of solver brokerages. J Strateg Inf Syst 21:216-232. https://doi.org/10.1016/j.jsis.2012. 03.002

Franke N, Keinz P, Klausberger K (2013) “Does This Sound Like a Fair Deal?": Antecedents and Consequences of Fairness Expectations in the Individual's Decision to Participate in Firm Innovation. Organ Sci 24(5):1495-1516. https://doi.org/10.1287/orsc.1120.0794

Frey K, Lüthje C, Haag S (2011) Whom should firms attract to open innovation platforms? The role of knowledge diversity and motivation. Long Range Plann 44:397-420. https://doi.org/10.1016/j.lrp. 2011.09.006

Galateanu E, Avasilcai S (2017) Emerging Creative Ecosystems: Platform Development Process. Ann ORADEA Univ Fascicle Manag Technol Eng Volume XXV. https://doi.org/10.15660/auofmte. 2017-3.3296

Galeano CP, Gaviria PA (2016) Open Innovation models, A literature review with a focus on SMEs. Iber Conf Inf Syst Technol Cist. https://doi.org/10.1109/CISTI.2016.7521534

Gassmann O, Enkel E, Chesbrough H (2010) The future of open innovation. R\&D Manag 40:213-221. https://doi.org/10.1111/j.1467-9310.2010.00605.x

Geiger D, Schader M (2014) Personalized task recommendation in crowdsourcing information systems - Current state of the art. Decis Support Syst 65:3-16. https://doi.org/10.1016/j.dss.2014.05.007

Ghezzi A, Gabelloni D, Martini A, Natalicchio A (2018) Crowdsourcing: A Review and Suggestions for Future Research. Int J Manag Rev 20:343-363. https://doi.org/10.1111/ijmr.12135

Gürtler MR, Lindemann U (2013) Situative open innovation - A model for selecting the right external actors and involving them in an efficient way. Proc Int Conf Eng Des ICED 3(DS75-03):259-268

Hertel G, Niedner S, Herrmann S (2003) Motivation of software developers in open source projects: An Internet-based survey of contributors to the Linux kernel. Res Policy 32:1159-1177. https://doi. org/10.1016/S0048-7333(03)00047-7

Holgersson M, Granstrand O, Bogers M (2018) The evolution of intellectual property strategy in innovation ecosystems: Uncovering complementary and substitute appropriability regimes. Long Range Plann. https://doi.org/10.1016/j.lrp.2017.08.007

Hossain M, Kauranen I (2015) Crowdsourcing: A comprehensive literature review. Strateg Outsourcing 8:2-22. https://doi.org/10.1108/SO-12-2014-0029

Hossain M, Kauranen I (2016) Open innovation in SMEs: a systematic literature review. J Strateg Manag 9:58-73. https://doi.org/10.1108/JSMA-08-2014-0072

Hossain M, Islam KMZ, Sayeed MA, Kauranen I (2016) A comprehensive review of open innovation literature. J Sci Technol Policy Manag 7:2-25. https://doi.org/10.1108/JSTPM-02-2015-0009

Hosseini M, Shahri A, Phalp K et al (2015) Crowdsourcing: A taxonomy and systematic mapping study. Comput Sci Rev 17:43-69. https://doi.org/10.1016/j.cosrev.2015.05.001

Howe J (2008) Crowdsourcing: Why the power of the Crowd is Driving the Future of Business. Crown Publishing Group, New York

Howells J (2006) Intermediation and the role of intermediaries in innovation. Res Policy 35:715-728. https://doi.org/10.1016/j.respol.2006.03.005

Huizingh EKRE (2011) Open innovation: state of the art and future perspectives. Technovation 31:2-9. https://doi.org/10.1016/j.technovation.2010.10.002

Hutter K, Hautz J, Füller J, Mueller J, Matzler K (2011) Communitition: The tension between competition and collaboration in community-based design contests. Creativity Innov Manag 20(1) 3-21. https://doi.org/10.1111/j.1467-8691.2011.00589.x

Jayakumar T (2016) Talenthouse India: crowdsourcing the Indian national anthem. J Bus Strategy 37:1223. https://doi.org/10.1108/JBS-06-2015-0064 
Kazai G, Kamps J, Milic-Frayling N (2013) An analysis of human factors and label accuracy in crowdsourcing relevance judgments. Inf Retrieval 16:138-178. https://doi.org/10.1007/ s10791-012-9205-0

Keupp MM, Palmié M, Gassmann O (2012) The Strategic Management of Innovation: A Systematic Review and Paths for Future Research. Int J Manag Rev 14:367-390. https://doi.org/10.1111/j. 1468-2370.2011.00321.x

Kohler T (2015) Crowdsourcing-based business models: How to create and capture value. Calif Manage Rev 57:63-84. https://doi.org/10.1525/cmr.2015.57.4.63

Kohler T (2018) How to Scale Crowdsourcing Platforms. Calif Manage Rev 60:98-121. https://doi.org/ $10.1177 / 0008125617738261$

Kohler T, Nickel M (2017) Crowdsourcing business models that last. J Bus Strategy 38:25-32. https:// doi.org/10.1108/JBS-10-2016-0120

Körpeoglu E, Cho SH (2018) Incentives in contests with heterogeneous solvers. Manage Sci 64:27092715. https://doi.org/10.1287/mnsc.2017.2738

Kovács A, Van Looy B, Cassiman B (2015) Exploring the scope of open innovation: a bibliometric review of a decade of research. Scientometrics 104:951-983. https://doi.org/10.1007/s11192-015-1628-0

Lee H (2016) Collective intelligence-based idea platform with linked data. Int Conf Big Data Smart Comput BigComp. https://doi.org/10.1109/BIGCOMP.2016.7425984

Leimeister J, Huber M, Bretschneider U, Krcmar H (2009) Leveraging crowdsourcing: activation-supporting components for IT-based ideas competition. J Manag Inf Syst 26:197-224. https://doi.org/ 10.2753/MIS0742-1222260108

Lessl M, Asadullah K (2014) Collaborative Innovation in Pharmaceutical Industry: approaches and Requirements. Collab Innov Drug Discov Strateg Public Priv Partnerships. https://doi.org/10.1002/ 9781118778166.ch16

Liang X, He M (2017) A co-citation bibliometric analysis of crowdsourcing research In: Proceedings of The 17th International Conference on Electronic Business, pp. 1-12. ICEB, Dubai, UAE, December 4-8

Lilien GL, Morrison PD, Searls K et al (2002) Performance assessment of the lead user idea-generation process for new product development. Manage Sci 48:1042-1059. https://doi.org/10.1287/mnsc. 48.8.1042.171

López-Robles JR, Otegi-Olaso JR, Porto Gomez I, et al (2018) Bibliometric network analysis to identify the intellectual structure and evolution of the big data research field. In: Yin H, Camacho D, Novais P, Tallón-Ballesteros A (eds) Intelligent Data Engineering and Automated Learning - IDEAL 2018. IDEAL 2018. Lect Notes Comput Sci, vol 11315. Springer, Cham, pp 113-120. https://doi. org/10.1007/978-3-030-03496-2_13

Lopez-Vega H, Tell F, Vanhaverbeke W (2016) Where and how to search? Search paths in open innovation. Res Policy 45:125-136. https://doi.org/10.1016/j.respol.2015.08.003

Lubicz M (2017) Applications of operations research and intelligent techniques in the health systems: A bibliometric analysis. Adv Intell Syst Comput 523:91-107. https://doi.org/10.1007/ 978-3-319-46589-0_8

Lüttgens D, Pollok P, Antons D, Piller F (2014) Wisdom of the crowd and capabilities of a few: internal success factors of crowdsourcing for innovation. J Bus Econ 84:339-374. https://doi.org/10.1007/ s11573-014-0723-7

Majchrzak A, Malhotra A (2013) Towards an information systems perspective and research agenda on crowdsourcing for innovation. J Strateg Inf Syst 22:257-268. https://doi.org/10.1016/j.jsis.2013. 07.004

Marjanovic S, Fry C, Chataway J (2012) Crowdsourcing based business models: In search of evidence for innovation 2.0. Sci Public Policy 39:318-332. https://doi.org/10.1093/scipol/scs009

Mas-Tur A, Kraus S, Brandtner M et al (2020) Advances in management research: a bibliometric overview of the review of managerial science. Rev Manag Sci 14:933-958. https://doi.org/10.1007/ s11846-020-00406-Z

Mazzola E, Acur N, Piazza M, Perrone G (2018) “To Own or Not to Own?" A study on the determinants and consequences of alternative intellectual property rights arrangements in crowdsourcing for innovation contests. J Prod Innov Manag 35:908-929. https://doi.org/10.1111/jpim.12467

McCain KW (1990) Mapping authors in intellectual space: A technical overview. J Am Soc Inf Sci 41:433-443. https://doi.org/10.1097/00005650-197905001-00025 
Mergel I (2015) Opening Government: Designing Open Innovation Processes to Collaborate With External Problem Solvers. Soc Sci Comput Rev 33:599-612. https://doi.org/10.1177/0894439314 560851

Mergel I, Desouza KC (2013) Implementing open innovation in the public sector: the case of challenge. gov. Public Adm Rev 73(6):882-890. https://doi.org/10.1111/puar.12141

Merz AB (2018) Mechanisms to select ideas in crowdsourced innovation contests - A systematic literature review and research agenda. In: 26th Eur Conf Inf Syst Beyond Digit - Facet Socio-Technical Chang ECIS 2018

Moellers T, Visini C, Haldimann M (2018) Complementing open innovation in multi-business firms: practices for promoting knowledge flows across internal units. R D Manag. https://doi.org/10.1111/ radm. 12343

Moon MJ (2018) Evolution of co-production in the information age: crowdsourcing as a model of webbased co-production in korea. Policy Soc 37:294-309. https://doi.org/10.1080/14494035.2017. 1376475

Natalicchio A, Ardito L, Savino T, Albino V (2017) Managing knowledge assets for open innovation: A systematic literature review. J Knowl Manag 21:1362-1383. https://doi.org/10.1108/ JKM-11-2016-0516

Niu X, Qin S, Zhang H et al (2018) Exploring product design quality control and assurance under both traditional and crowdsourcing-based design environments. Adv Mech Eng 10:1-23. https://doi.org/ $10.1177 / 1687814018814395$

Nylund PA, Ferras-Hernandez X, Brem A (2020) Automating profitably together: Is there an impact of open innovation and automation on firm turnover? Rev Manag Sci. https://doi.org/10.1007/ s11846-018-0294-z

O’Mahony S, Ferraro F (2007) The emergence of governance in an open source community. Acad Manag J 50:1079-1106. https://doi.org/10.5465/AMJ.2007.27169153

Palacios M, Martinez-Corral A, Nisar A, Grijalvo M (2016) Crowdsourcing and organizational forms: Emerging trends and research implications. J Bus Res 69:1834-1839. https://doi.org/10.1016/j. jbusres.2015.10.065

Perkmann M, Walsh K (2007) University-industry relationships and open innovation: Towards a research agenda. Int J Manag Rev 9:259-280. https://doi.org/10.1111/j.1468-2370.2007.00225.x

Piazza M, Mazzola E, Acur N, Perrone G (2019) Governance considerations for seeker-solver relationships: a knowledge-based perspective in crowdsourcing for innovation contests. Br J Manag 30:810-828. https://doi.org/10.1111/1467-8551.12327

Piezunka H, Dahlander L (2015) Distant search, narrow attention: how crowding alters organizations' filtering of suggestions in crowdsourcing. Acad Manag J 58:856-880. https://doi.org/10.1520/JTE12 $271 \mathrm{~J}$

Pittaway L, Robertson M, Munir K et al (2004) Networking and innovation: a systematic review of the evidence. Int J Manag Rev 5(6):137-168

Poetz MK, Schreier M (2012) The value of crowdsourcing: can users really compete with professionals in generating new product ideas? J Prod Innov Manag 29:245-256. https://doi.org/10.1111/j.15405885.2011.00893.x

Pollok P, Lüttgens D, Piller FT (2019b) Attracting solutions in crowdsourcing contests: the role of knowledge distance, identity disclosure, and seeker status. Res Policy 48:98-114. https://doi.org/10. 1016/j.respol.2018.07.022

Pollok P, Lüttgens D, Piller FT (2019a) How firms develop capabilities for crowdsourcing to increase open innovation performance: the interplay between organizational roles and knowledge processes. J Prod Innov Manag 36:412-441. https://doi.org/10.1111/jpim.12485

Poole MS, van de Ven AH (1989) Using Paradox to Build Management and Organization Theories. Acad Manag Rev. https://doi.org/10.5465/amr.1989.4308389

Rahman H (2016) Open innovation: Reaching out to the grass roots through SMEs - exploring issues of opportunities and challenges to reach economic sustainability. In: Human Development and Interaction in the Age of Ubiquitous Technology. IGI Global, Hershey, PA, pp 273-307

Ramos I, Cardoso M, Carvalho JV, Graça JI (2009) An action research on open knowledge and technology transfer. IFIP Adv Inf Commun Technol 301:211-223. https://doi.org/10.1007/978-3-64202388-0_15

Randhawa K, Wilden R, Hohberger J (2016) A Bibliometric Review of Open Innovation: Setting a Research Agenda. J Prod Innov Manag 33:750-772. https://doi.org/10.1111/jpim.12312 
Remneland Wikhamn B, Wikhamn W (2013) Structuring of the open innovation field. J Technol Manag Innov 8:173-185. https://doi.org/10.4067/s0718-27242013000400016

Rouse AC (2010) A preliminary taxonomy of crowdsourcing. In: ACIS 2010 Proceedings, 76

Saez-Rodriguez J, Costello JC, Friend SH et al (2016) Crowdsourcing biomedical research: Leveraging communities as innovation engines. Nat Rev Genet 17:470-486. https://doi.org/10.1038/nrg.2016. 69

Santana M, Lopez-Cabrales A (2019) Sustainable development and human resource management: A science mapping approach. Corp Soc Responsib Environ Manag 26:1171-1183. https://doi.org/10. 1002/csr. 1765

Santoro G, Vrontis D, Thrassou A, Dezi L (2018) The Internet of Things: Building a knowledge management system for open innovation and knowledge management capacity. Technol Forecast Soc Change 136:347-354. https://doi.org/10.1016/j.techfore.2017.02.034

Sawhney M, Verona G, Prandelli E (2005) Collaborating to create: the internet as a platform for customer engagement in product innovation. J Interact Mark 19:4-17. https://doi.org/10.1002/dir.20046

Saxton GD, Oh O, Kishore R (2013) Rules of Crowdsourcing: Models, Issues, and Systems of Control. Inf Syst Manag 30:2-20. https://doi.org/10.1080/10580530.2013.739883

Schaefer D, Forbes HL (2019) Social Product Development is Finding Its Way into Industry. Steel Times Int

Schemmann B, Herrmann AM, Chappin MMH, Heimeriks GJ (2016) Crowdsourcing ideas: involving ordinary users in the ideation phase of new product development. Res Policy 45:1145-1154. https://doi.org/10.1016/j.respol.2016.02.003

Schenk E, Guittard C, Pénin J (2019) Open or proprietary? Choosing the right crowdsourcing platform for innovation. Technol Forecast Soc Change 144:303-310. https://doi.org/10.1016/j.techfore. 2017.11.021

Schlagwein D, Bjørn-andersen N (2014) Organizational learning with crowdsourcing : the revelatory case of LEGO. J Assoc Inf Syst 15:754-778

Schuhmacher A, Gassmann O, McCracken N, Hinder M (2018) Open innovation and external sources of innovation. An opportunity to fuel the R\&D pipeline and enhance decision making? J Transl Med 16:1-14. https://doi.org/10.1186/s12967-018-1499-2

Secundo G, Toma A, Schiuma G, Passiante G (2019) Knowledge transfer in open innovation: A classification framework for healthcare ecosystems. Bus Process Manag J 25:144-163. https://doi.org/10. 1108/BPMJ-06-2017-0173

Seltzer E, Mahmoudi D (2013) Citizen Participation, Open Innovation, and Crowdsourcing: Challenges and Opportunities for Planning. J Plan Lit 28:3-18. https://doi.org/10.1177/0885412212469112

Sieg JH, Wallin MW, Von Krogh G (2010) Managerial challenges in open innovation: a study of innovation intermediation in the chemical industry. R D Manag. https://doi.org/10.1111/j.1467-9310. 2009.00596.x

Silva C, Ramos I (2011) Knowledge Metamodel For Crowdsourcing Innovation Intermediaries Open Innovation. In: Creating Global Competitive Economies: A 360-Degree Approach - Proc of the 17th Int Bus Inf Manag Assoc Conf, IBIMA 2011, pp 2099-2111

Silva C, Ramos I (2012) Crowdsourcing Innovation Intermediaries Functions. In: Proc of MCIS 2012 7th Mediterr Conf on Inf Sys

Small H (1973) Co-citation in the scientific literature : a new measure of the relationship between two documents. J Am Soc Inf Sci 24:265-269

Stanko MA, Fisher GJ, Bogers M (2017) Under the wide umbrella of open innovation. J Prod Innov Manag 34:543-558. https://doi.org/10.1111/jpim.12392

Surowiecki J (2005) The wisdom of crowds. Anchor Books, New York

Terwiesch C, Xu Y (2008) Innovation contests, open innovation, and multiagent problem solving. Manage Sci 54:1529-1543. https://doi.org/10.1287/mnsc.1080.0884

Tranfield D, Denyer D, Smart P (2003) Towards a methodology for developing evidence-informed management knowledge by means of systematic review. Br J Manag 14:207-222. https://doi.org/10. $2307 / 249689$

Urbinati A, Chiaroni D, Chiesa V, Frattini F (2020) The role of digital technologies in open innovation processes: an exploratory multiple case study analysis. R\&D Manag 50(1):136-160. https://doi. org/10.1111/radm.12313

van der Vegt RG (2018) A literature review on the relationship between risk governance and public engagement in relation to complex environmental issues. J Risk Res 21:1-18. https://doi.org/10. 1080/13669877.2017.1351466 
van Eck NJ, Waltman L (2009) How to normalize cooccurrence data? An analysis of somewell-known similarity measures. J Am Soc Inf Sci Technol 60:1635-1651. https://doi.org/10.1002/asi

Vanhaverbeke W, Van de Vrande V, Cloodt M (2008) Connecting absorptive capacity and open innovation. SSRN Electron J. https://doi.org/10.2139/ssrn.1091265

von Hippel E (2005) Democratizing innovation: the evolving phenomenon of user innovation. J Fur Betriebswirtschaft 55:63-78. https://doi.org/10.1007/s11301-004-0002-8

Von Hippel E, Von Krogh G (2003) Open source software and the "private-collective" innovation model: Issues for organization science. Organ Sci 14:209-223+225. https://doi.org/10.2139/ssrn.1410789

Vuković M (2009) Crowdsourcing for enterprises. In: Proceedings of the 2009 Congress on Services - I, IEEE Computer Society (Washington, DC, USA 2009), pp 686-692. https://doi.org/10.1109/ SERVICES-I.2009.56

West J, Bogers M (2014) Leveraging external sources of innovation: a review of research on open innovation. J Prod Innov Manag 31:814-831. https://doi.org/10.1111/jpim.12125

West J, O'mahony S, (2008) The role of participation architecture in growing sponsored open source communities. Ind Innov 15:145-168. https://doi.org/10.1080/13662710801970142

Whitla P (2009) Crowdsourcing and Its Application in Marketing Activities. Contemp Manag Res 5:1528. https://doi.org/10.7903/cmr.1145

Wilson KB, Bhakoo V, Samson D (2018) Crowdsourcing: a contemporary form of project management with linkages to open innovation and novel operations. Int J Oper Prod Manag 38:1467-1494. https://doi.org/10.1108/IJOPM-12-2016-0753

Xu C, Qin S, Xiao Z (2012) Crowdsourcing based product innovation design service model for smalland medium-sized enterprises. In: ICAC 12 - Proc of the 18th Int Conf on Autom and Comput. IEEE, pp 1-5

Zhao Y, Zhu Q (2014) Evaluation on crowdsourcing research: current status and future direction. Inf Syst Front 16:417-434. https://doi.org/10.1007/s10796-012-9350-4

Zupic I, Čater T (2015) Bibliometric methods in management and organization. Organ Res Methods 18:429-472. https://doi.org/10.1177/1094428114562629

Publisher's Note Springer Nature remains neutral with regard to jurisdictional claims in published maps and institutional affiliations.

\section{Authors and Affiliations}

\section{Livio Cricelli ${ }^{1}$ (D) Michele Grimaldi ${ }^{2}$. Silvia Vermicelli ${ }^{3}$}

Livio Cricelli

livio.cricelli@unina.it

Michele Grimaldi

m.grimaldi@unicas.it

1 Department of Industrial Engineering, University of Naples "Federico II", Piazzale Tecchio 80, Naples, Italy

2 Department of Civil and Mechanical Engineering, University of Cassino and Southern Lazio, Via G. Di Biasio 43, Cassino, Frosinone, Italy

3 Department of Enterprise Engineering, University of Rome "Tor Vergata”, Viale del Politecnico, 1, 00133 Rome, Italy 